\title{
Catalytic Conjugate Additions of Carbonyl Anions Under Neutral Aqueous Conditions
}

\author{
Michael C. Myers, Ashwin R. Bharadwaj, Benjamin C. Milgram and Karl A. Scheidt* \\ Department of Chemistry, Northwestern University, 2145 Sheridan Road, Evanston, Illinois 60208
}

\section{Supplemental Section Table of Contents}

1. General methods

2. Procedure and characterization data for $\mathbf{I}$

3. General procedures (A \& B) and characterization data for $\alpha, \beta$-unsaturated-2-acyl-imidazole substrates $\mathbf{6 , 8 a - 1 7 a}$

4. General procedure $\mathrm{C}$ for converting $\alpha$-keto acids to the sodium carboxylate salts

5. General procedure D and characterization data of acyl anion addition products $\mathbf{7 - 2 4}$

6. Larger scale $(5 \mathrm{mmol})$ preparation of 7

7. General procedure $\mathrm{E}$ for the preparation of $\mathbf{8}$ and $\mathbf{1 0}$ in ethylene glycol at $23{ }^{\circ} \mathrm{C}$

8. Experimental details of the product inhibition study

9. Procedures and characterization data for the conversion of 7 to the methyl ester $\mathbf{2 6}$ and morpholine amide $\mathbf{2 7}$

10. Selected NMR Spectra
S1-S2

S2-S3

S3-S6

S6-S7

S7-S12

S12-S13

S13

$\mathrm{S} 13-\mathrm{S} 14$

S15-S17

S18-S27

General Methods: Tetrahydrofuran (THF) was purified by passage through a bed of activated alumina. ${ }^{1}$ EtOH (200 proof), $\mathrm{MeOH}$ (HPLC grade), and Ethylene glycol (Fisher, certified grade) were used without further purification. Deionized water was used to make the buffered solutions. Purification of reaction products was carried out by flash chromatography using EM Reagent silica gel 60 (230-400 mesh). Analytical thin layer chromatography was performed on

${ }^{1}$ Pangborn, A. B.; Giardello, M. A.; Grubbs, R. H.; Rosen, R. K.; Timmers, F. J. Organometal. 1996, 15, 15181520. 
EM Reagent $0.25 \mathrm{~mm}$ silica gel 60-F plates. Visualization was accomplished with UV light and potassium permangenate, or phosphomolybic acid stains followed by heating. Melting points (mp) were obtained on a Thomas Hoover Capillary Melting Point Apparatus and are uncorrected. Infrared spectra (IR) were obtained on a Bio-Rad FTS-40 FTIR spectrophotometer. Infrared spectra for liquid products were obtained as a thin film on a $\mathrm{KBr}$ disk, and spectra for solid products were collected by preparing a $\mathrm{KBr}$ pellet containing the title compound. Proton nuclear magnetic resonances $\left({ }^{1} \mathbf{H}\right.$ NMR) were recorded in deuterated solvents on a Varian Inova $500(500 \mathrm{MHz})$ spectrometer. Chemical shifts are reported in parts per million (ppm, $\delta)$ relative to tetramethylsilane $(\delta 0.00)$. If tetramethylsilane was not present in the deuterated solvent, the residual protio solvent is referenced $\left(\mathrm{CDCl}_{3}, \delta 7.27 ; \mathrm{D}_{2} \mathrm{O}, \delta\right.$ 4.80; DMSO, $\left.\delta 2.50\right){ }^{1} \mathrm{H}$ NMR splitting patterns are designated as singlet (s), doublet (d), triplet (t), quartet (q), or septet (sep). Splitting patterns that could not be interpreted or easily visualized are designated as multiplet (m) or broad (br). Coupling constants are reported in Hertz (Hz). Proton-decoupled $\left({ }^{13} \mathbf{C}-\mathbf{N M R}\right)$ spectra were recorded on a Varian Inova $500(125 \mathrm{MHz})$ spectrometer and are reported in ppm using the solvent as an internal standard $\left(\mathrm{CDCl}_{3}, \delta\right.$ 77.0; DMSO, $\delta$ 39.5). Electrospray mass spectra (ESI-MS) were obtained using a Micromass Quattro II Triple Quadrupole HPLC/MS/MS Mass Spectrometer. Gas Chromatography (GC) analysis data were obtained on Hewlett Packard 6890 Series GC System with a 7683 Series Injector. An HP-5 capillary $30 \mathrm{~m}$ column was employed (19091J-413). Methyl trifluoromethanesulfonate was distilled prior to use. Unless otherwise noted, all other commercially available reagents and solvents were purchased from Aldrich and used without further purification.

Abbreviations: (DABCO), 1,4-diazabicyclo[2.2.2] octane; (DBU), 1,8 diazabicyclo[5.4.0.]undec-7-ene; (DMAP), 4-(dimethylamino)pyridine; (RBF), round bottom flask .

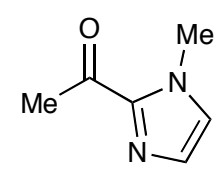

2-acetyl-1-methylimidazole (I): 4-acetylmorpholine (11.6 mL, $100 \mathrm{mmol}, 1.0$ equiv) and THF $(100 \mathrm{~mL})$ were added to a $500 \mathrm{~mL} \mathrm{RBF}$ and cooled to $-78^{\circ} \mathrm{C}$. 1 methylimidazole ( $8.8 \mathrm{~mL}, 110 \mathrm{mmol}, 1.1$ equiv) and THF $(75 \mathrm{~mL})$ were added to a $250 \mathrm{~mL}$ RBF and cooled to $0{ }^{\circ} \mathrm{C}$. A solution of BuLi in hexanes $(1.4 \mathrm{M}, 78.6 \mathrm{~mL}, 110 \mathrm{mmol}$, 1.1 equiv) was added to the $250 \mathrm{~mL}$ RBF over $5 \mathrm{~min}$. The solution was allowed to stir at $0{ }^{\circ} \mathrm{C}$ for $10 \mathrm{~min}$. The lithiated imidazole solution was then cannula transferred to the $500 \mathrm{~mL} \mathrm{RBF}$ over 15 min and stirred for $1 \mathrm{~h}$ at $-78^{\circ} \mathrm{C}$. After stirring $1 \mathrm{~h}$ the solution was taken out of the -78 ${ }^{\circ} \mathrm{C}$ bath and stirred for $15 \mathrm{~min}$. The solution was quenched with $\mathrm{HCl}(1.0 \mathrm{M}, 10 \mathrm{~mL})$, stirred for 
5 min, and saturated $\mathrm{NaCl}(30 \mathrm{~mL})$ and saturated $\mathrm{NaHCO}_{3}(30 \mathrm{~mL})$ were added. The resulting mixture was transferred to a separatory funnel, and extracted with EtOAc $(3 \times 100 \mathrm{~mL})$. The organic extracts were combined and dried over sodium sulfate. The solution was concentrated on a rotatory evaporator and dried under vacuum to give a pale orange oil. The unpurified oil was enriched in the product $\left(\sim 90 \%,{ }^{1} \mathrm{H}\right.$ NMR) and used without further purification. A portion was purified by flash column chromatography $\left(90 \% \mathrm{Et}_{2} \mathrm{O} /\right.$ hexane, colorless oil) to obtain an analytically pure sample for the characterization data. $\mathrm{R} f=0.30$ (90\% ether/hexanes); ${ }^{1} \mathrm{H}$ NMR $\left(500 \mathrm{MHz}, \mathrm{CDCl}_{3}\right) \delta 7.12(\mathrm{~s}, 1 \mathrm{H}), 7.01(\mathrm{~s}, 1 \mathrm{H}), 3.98$ (s, 3H), 2.64 (s, 3H); LRMS (electrospray): Mass calculated for $\mathrm{C}_{6} \mathrm{H}_{8} \mathrm{~N}_{2} \mathrm{O}[\mathrm{M}]^{+}, 124.14$. Found 124. Spectroscopic data were consistent with the literature data for this compound. ${ }^{2,3}$

\section{General Procedure (A) to Form $\alpha, \beta$-Unsaturated Substrates ${ }^{4}$}

2-acetyl-1-methylimidazole (I) (1.24 g, $10.0 \mathrm{mmol}, 1.0$ equiv) and EtOH $(20 \mathrm{~mL})$ were added to a $100 \mathrm{~mL}$ RBF followed by the desired aromatic aldehyde (10.0 mmol, 1.0 equiv) and a catalytic amount of $\mathrm{KOH}$ ( 2 pellets, $\sim 100 \mathrm{mg}$ ). The solution was stirred for 1-12 $\mathrm{h}$ depending upon how quickly the product precipitated from the solution. The solution was filtered and the product was washed with water $(20 \mathrm{~mL})$ and $\mathrm{EtOH}(25 \mathrm{~mL})$.

\section{General Procedure (B) to Form $\alpha, \beta$-Unsaturated Substrates ${ }^{4}$}

2-acetyl-1-methylimidazole (I) (1.24 g, $10.0 \mathrm{mmol}, 1.0$ equiv) and EtOH (20 mL) were added to a $100 \mathrm{~mL}$ RBF followed by the desired aromatic aldehyde (10.0 mmol, 1.0 equiv) and a catalytic amount of $\mathrm{KOH}$ ( 2 pellets, $100 \mathrm{mg}$ ). The solution was stirred for $12 \mathrm{~h}$ then transferred to a separatory funnel. Saturated $\mathrm{NaCl}(30 \mathrm{~mL})$ and $\mathrm{H}_{2} \mathrm{O}(10 \mathrm{~mL})$ were added and the mixture was extracted with EtOAc $(4 \times 75 \mathrm{~mL})$. The combined organic extracts were dried over sodium sulfate, filtered, and concentrated on a rotatory evaporator. The resulting residue was purified by flash column chromatography on silica gel.

2 Davies, D. H.; Hall, J.; Smith, E. H. J. Chem. Soc. Perkin Trans. 1 1991, 2691-2698.

3 Abarca, B. G.; Jones, A. R.; Medio, M. S.; Quilez, P. J.; Sepulveda, J. A.; Zaballos, G. E. Synth. Commun. 1990, 321-331.

${ }^{4}$ Hayakawa, S.; Michiue, T.; Okamoto, M.; Hatakeyama, S.; Ohta, S. Heterocycles 1980, 647-650. 


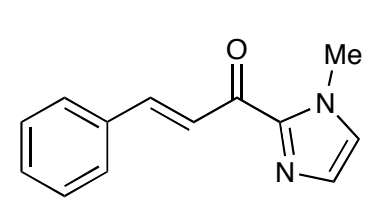
$3 \mathrm{H}) ;{ }^{13} \mathrm{C}$ NMR $\left(125 \mathrm{MHz}, \mathrm{CDCl}_{3}\right) \delta 180.4,144.0,143.3,134.8,130.4,129.3,128.8,128.7$, 127.2, 122.7, 36.3; LRMS (electrospray): Mass calculated for $\mathrm{C}_{13} \mathrm{H}_{12} \mathrm{~N}_{2} \mathrm{O}[\mathrm{M}]^{+}, 212.25$. Found 213.<smiles>Cc1ccc(/C=C/C(=O)c2nccn2C)cc1</smiles>

(E)-1-(1-methyl-1 $H$-imidazol-2-yl)-3-p-tolylprop-2-en-1-one (8a): Prepared following general procedure (B), purified with $40 \%$ EtOAc/hexanes, to give $1.20 \mathrm{~g}(55 \%)$ of $\mathbf{8 a}$ as an off-white solid. $\mathrm{R} f$ $=0.33$ (40\% ether/hexanes); $\mathrm{mp}=84-86{ }^{\circ} \mathrm{C}$; IR (film) $3103,3028,1654,1598 \mathrm{~cm}^{-1} ;{ }^{1} \mathrm{H}$ NMR $\left(500 \mathrm{MHz}, \mathrm{CDCl}_{3}\right) \delta 8.04(\mathrm{~d}, J=16.0,1 \mathrm{H}), 7.80(\mathrm{~d}, J=16.5 \mathrm{~Hz}, 1 \mathrm{H}), 7.59(\mathrm{~d}, J=7.5 \mathrm{~Hz}, 2 \mathrm{H})$, $7.20(\mathrm{~m}, 2 \mathrm{H}), 7.19(\mathrm{~s}, 1 \mathrm{H}), 7.05(\mathrm{~s}, 1 \mathrm{H}), 4.07(\mathrm{~s}, 3 \mathrm{H}), 2.36(\mathrm{~s}, 3 \mathrm{H}) ;{ }^{13} \mathrm{C} \mathrm{NMR}\left(125 \mathrm{MHz}, \mathrm{CDCl}_{3}\right)$ $\delta 180.4,144.0,143.3,140.8,132.1,129.5,129.1,128.6,127.1,121.6,36.2,21.4$; LRMS (electrospray): Mass calculated for $\mathrm{C}_{14} \mathrm{H}_{14} \mathrm{~N}_{2} \mathrm{O}[\mathrm{M}]^{+}, 226.27$. Found 227 .<smiles>COc1ccc(/C=C/C(=O)c2nccn2C)cc1</smiles>

(E)-3-(4-methoxyphenyl)-1-(1-methyl-1H-imidazol-2-yl)prop-2en-1-one (9a): Prepared following general procedure (A) to give $1.24 \mathrm{~g}(51 \%)$ of $9 \mathrm{a}$ as an off-white solid. $\mathrm{R} f=0.39(90 \%$ ether/hexanes); $\mathrm{mp}=115-116^{\circ} \mathrm{C}$; IR (film) $3111,1652,1590 \mathrm{~cm}^{-1}$; ${ }^{1} \mathrm{H}$ NMR $\left(500 \mathrm{MHz}, \mathrm{CDCl}_{3}\right) \delta 7.95(\mathrm{~d}, J=15.5 \mathrm{~Hz}, 1 \mathrm{H}), 7.80(\mathrm{~d}, J$ $=16.0 \mathrm{~Hz}, 1 \mathrm{H}), 7.65(\mathrm{~d}, J=8.5 \mathrm{~Hz}, 2 \mathrm{H}), 7.21(\mathrm{~s}, 1 \mathrm{H}), 7.06(\mathrm{~s}, 1 \mathrm{H}), 6.92(\mathrm{~d}, J=8.5 \mathrm{~Hz}, 2 \mathrm{H})$, 4.09 (s, 3H), $3.84(\mathrm{~s}, 3 \mathrm{H}) ;{ }^{13} \mathrm{C}$ NMR $\left(125 \mathrm{MHz}, \mathrm{CDCl}_{3}\right) \delta 180.5,161.6,144.1,143.2,130.5$, 129.1, 127.6, 127.0, 120.4, 114.2, 55.3, 36.3; LRMS (electrospray): Mass calculated for $\mathrm{C}_{13} \mathrm{H}_{12} \mathrm{~N}_{2} \mathrm{O}_{2}[\mathrm{M}]^{+}, 242.47$. Found 243.

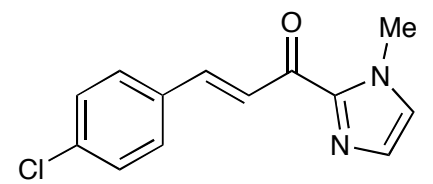

(E)-3-(4-chlorophenyl)-1-(1-methyl-1H-imidazol-2-yl)prop-2-en1-one (10a): Prepared following general procedure (A) to give $1.73 \mathrm{~g}$ $(70 \%)$ of $10 \mathrm{a}$ as an off-white solid. $\mathrm{R} f=0.38(90 \%$ ether/hexanes); $\mathrm{mp}=125-127{ }^{\circ} \mathrm{C}$; IR (film) 3106, 1656, $1597 \mathrm{~cm}^{-1} ;{ }^{1} \mathrm{H}$ NMR $(500$ $\left.\mathrm{MHz}, \mathrm{CDCl}_{3}\right) \delta 8.04(\mathrm{~d}, J=15.5 \mathrm{~Hz}, 1 \mathrm{H}), 7.75(\mathrm{~d}, J=15.5 \mathrm{~Hz}, 1 \mathrm{H})$, $7.61(\mathrm{~d}, J=8.5 \mathrm{~Hz}, 2 \mathrm{H}), 7.37(\mathrm{~d}, J=8.0 \mathrm{~Hz}, 2 \mathrm{H}), 7.22(\mathrm{~s}, 1 \mathrm{H}), 7.09(\mathrm{~s}, 1 \mathrm{H}), 4.09(\mathrm{~s}, 3 \mathrm{H}) ;{ }^{13} \mathrm{C}$ NMR $\left(125 \mathrm{MHz}, \mathrm{CDCl}_{3}\right) \delta 180.1,143.8,141.7,136.2,133.3,129.8,129.3,129.0,127.3,123.2$, 36.3; LRMS (electrospray): Mass calculated for $\mathrm{C}_{13} \mathrm{H}_{11} \mathrm{ClN}_{2} \mathrm{O}[\mathrm{M}]^{+}$, 246.69. Found 247.

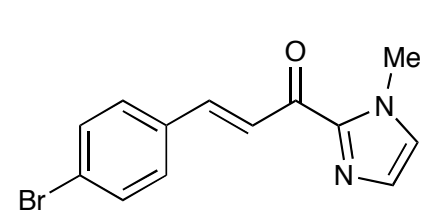

(E)-3-(4-bromophenyl)-1-(1-methyl-1H-imidazol-2-yl)prop-2-en-

1-one (11a): Prepared following general procedure (A) to give $1.75 \mathrm{~g}$ $(60 \%)$ of $11 \mathrm{a}$ as an off-white solid. $\mathrm{R} f=0.45(90 \%$ ether/hexanes); $\mathrm{mp}=139-141{ }^{\circ} \mathrm{C}$; IR (film) $3108,1655,1597 \mathrm{~cm}^{-1} ;{ }^{1} \mathrm{H}$ NMR $(500$ $\left.\mathrm{MHz}, \mathrm{CDCl}_{3}\right) \delta 8.05(\mathrm{~d}, J=16.0,1 \mathrm{H}), 7.58(\mathrm{~d}, J=15.5 \mathrm{~Hz}, 1 \mathrm{H}), 7.53$ (m, 4H), $7.21(\mathrm{~s}, 1 \mathrm{H}), 7.08(\mathrm{~s}, 1 \mathrm{H}), 4.08(\mathrm{~s}, 3 \mathrm{H}) ;{ }^{13} \mathrm{C} \mathrm{NMR}\left(125 \mathrm{MHz}, \mathrm{CDCl}_{3}\right) \delta$ 180.0, 143.8, $141.7,133.7,132.0,130.0,129.3,127.3,124.6,123.3,36.3$; LRMS (electrospray): Mass 
calculated for $\mathrm{C}_{13} \mathrm{H}_{11} \mathrm{BrN}_{2} \mathrm{O}[\mathrm{M}]^{+}$, 291.14. Found 292 .

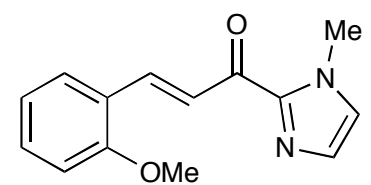

(E)-3-(2-methoxyphenyl)-1-(1-methyl-1H-imidazol-2-yl)prop-2-

en-1-one (12a): Prepared following general procedure (B), purified with $40 \% \mathrm{EtOAc} / \mathrm{hexanes}$, to give $1.57 \mathrm{~g}(65 \%)$ of $\mathbf{1 2 a}$ as an off-white solid. $\mathrm{R} f=0.45$ (90\% EtOAc/hexanes); $\mathrm{mp}=90-93{ }^{\circ} \mathrm{C}$; IR (film) 3106, 2957, 1657, $1595 \mathrm{~cm}^{-1} ;{ }^{1} \mathrm{H}$ NMR $\left(500 \mathrm{MHz}, \mathrm{CDCl}_{3}\right) \delta 8.05(\mathrm{~d}, J=15.5 \mathrm{~Hz}$, $1 \mathrm{H}), 7.79(\mathrm{~d}, J=15.5 \mathrm{~Hz}, 1 \mathrm{H}), 7.32-7.27(\mathrm{~m}, 2 \mathrm{H}), 7.21(\mathrm{~m}, 2 \mathrm{H}), 7.07(\mathrm{~s}, 1 \mathrm{H}), 6.94(\mathrm{~d}, J=7.5$ $\mathrm{Hz}, 1 \mathrm{H}), 4.08(\mathrm{~s}, 3 \mathrm{H}), 3.84(\mathrm{~s}, 3 \mathrm{H}) ;{ }^{13} \mathrm{C} \mathrm{NMR}\left(125 \mathrm{MHz}, \mathrm{CDCl}_{3}\right) \delta 180.3,159.8,143.9,143.2$, 136.1, 129.7, 129.2, 127.2, 122.8, 121.6, 116.6, 112.8, 55.2, 36.3; LRMS (electrospray): Mass calculated for $\mathrm{C}_{14} \mathrm{H}_{14} \mathrm{~N}_{2} \mathrm{O}_{2}[\mathrm{M}]^{+}, 242.27$. Found 243 .

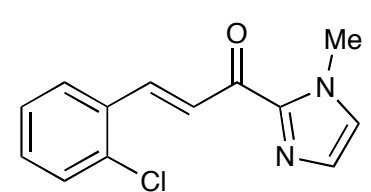

(E)-3-(2-chlorophenyl)-1-(1-methyl-1H-imidazol-2-yl)prop-2-en-

1-one (13a): Prepared following general procedure (A) to give $1.98 \mathrm{~g}$ $(80 \%)$ of $13 \mathrm{a}$ as a white solid. $\mathrm{R} f=0.38(90 \%$ ether/hexanes); $\mathrm{mp}=147$ $148{ }^{\circ} \mathrm{C}$; IR (film) 3130, 1656, $1603 \mathrm{~cm}^{-1} ;{ }^{1} \mathrm{H}$ NMR (500 MHz, $\left.\mathrm{CDCl}_{3}\right) \delta$ $8.26(\mathrm{~d}, J=16.0 \mathrm{~Hz}, 1 \mathrm{H}), 8.07(\mathrm{~d}, J=16.0 \mathrm{~Hz}, 1 \mathrm{H}), 7.87(\mathrm{~d}, J=7.0 \mathrm{~Hz}$, $1 \mathrm{H}), 7.42(\mathrm{~d}, J=7.0 \mathrm{~Hz}, 1 \mathrm{H}), 7.30(\mathrm{~m}, 2 \mathrm{H}), 7.22(\mathrm{~s}, 1 \mathrm{H}), 7.09(\mathrm{~s}, 1 \mathrm{H}), 4.10(\mathrm{~s}, 3 \mathrm{H}) ;{ }^{13} \mathrm{C}$ NMR $\left(125 \mathrm{MHz} \mathrm{CDCl}_{3}\right) \delta$ 179.9, 143.8, 138.8, 135.6, 133.0, 131.1, 130.1, 129.4, 127.9, 127.4, 126.9, 124.9, 36.3; LRMS (electrospray): Mass calculated for $\mathrm{C}_{13} \mathrm{H}_{11} \mathrm{ClN}_{2} \mathrm{O}[\mathrm{M}]^{+}, 246.69$. Found 247.

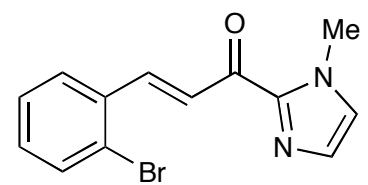

(E)-3-(2-bromophenyl)-1-(1-methyl-1H-imidazol-2-yl)prop-2-en-

1-one (14a): Prepared following general procedure (A) to give $2.78 \mathrm{~g}$ (95\%) of 14a as white solid. $\mathrm{R} f=0.38$ (90\% ether/hexanes); $\mathrm{mp}=142$ $143{ }^{\circ} \mathrm{C}$; IR (film) $3116,1659,1595 \mathrm{~cm}^{-1} ;{ }^{1} \mathrm{H}$ NMR $\left(500 \mathrm{MHz}, \mathrm{CDCl}_{3}\right) \delta$ $8.20(\mathrm{~d}, J=16.0 \mathrm{~Hz}, 1 \mathrm{H}), 8.03(\mathrm{~d}, J=16.0 \mathrm{~Hz}, 1 \mathrm{H}), 7.85(\mathrm{~d}, J=7.5 \mathrm{~Hz}$, $1 \mathrm{H}), 7.61(\mathrm{~d}, J=8.0 \mathrm{~Hz}, 1 \mathrm{H}), 7.33(\mathrm{t}, J=7.5 \mathrm{~Hz}, 1 \mathrm{H}), 7.24-7.21(\mathrm{~m}, 2 \mathrm{H}), 7.09(\mathrm{~s}, 1 \mathrm{H}), 4.09(\mathrm{~s}$, $3 \mathrm{H}) ;{ }^{13} \mathrm{C}$ NMR $\left(125 \mathrm{MHz}, \mathrm{CDCl}_{3}\right) \delta 179.8,143.8,141.3,134.7,133.3,131.2,129.3,128.0$, 127.5, 127.4, 126.0, 125.1, 36.3; LRMS (electrospray): Mass calculated for $\mathrm{C}_{13} \mathrm{H}_{11} \mathrm{BrN}_{2} \mathrm{O}[\mathrm{M}]^{+}$, 291.14. Found 292.

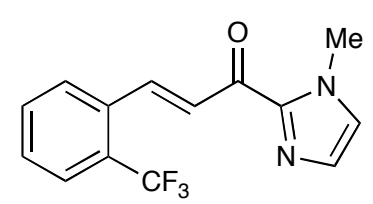

(E)-3-(2-(trifluoromethyl)phenyl)-1-(1-methyl-1H-imidazol-2-

yl)prop-2-en-1-one (15a): Prepared following general procedure (B), purified with $40 \%$ EtOAc/hexanes, to give $1.1 \mathrm{~g}(40 \%)$ of $\mathbf{1 5 a}$ as an offwhite solid. $\mathrm{R} f=0.35$ (90\% EtOAc/hexanes); $\mathrm{mp}=109-110{ }^{\circ} \mathrm{C}$; IR (film) 3110, 1654, $1599 \mathrm{~cm}^{-1} ;{ }^{1} \mathrm{H}$ NMR (500 MHz, $\left.\mathrm{CDCl}_{3}\right) \delta 8.20(\mathrm{~d}, J=$ $16.0 \mathrm{~Hz}, 1 \mathrm{H}), 8.08(\mathrm{~d}, J=15.5 \mathrm{~Hz}, 1 \mathrm{H}), 7.96(\mathrm{~d}, J=8.5 \mathrm{~Hz}, 1 \mathrm{H}), 7.71(\mathrm{~d}, J=7.5 \mathrm{~Hz}, 1 \mathrm{H}), 7.58$ $(\mathrm{t}, J=7.5 \mathrm{~Hz}, 1 \mathrm{H}), 7.48(\mathrm{t}, J=7.5 \mathrm{~Hz}, 1 \mathrm{H}), 7.22(\mathrm{~s}, 1 \mathrm{H}), 7.11(\mathrm{~s}, 1 \mathrm{H}), 4.10(\mathrm{~s}, 3 \mathrm{H}) ;{ }^{13} \mathrm{C} \mathrm{NMR}$ $\left(125 \mathrm{MHz}, \mathrm{CDCl}_{3}\right) \delta 179.6,143.7,138.2,133.7,131.9,129.6,129.4,128.1,127.5,126.0,126.0$, 126.0, 126.0, 125.0, 122.9, 36.3; LRMS (electrospray): Mass calculated for $\mathrm{C}_{14} \mathrm{H}_{11} \mathrm{~F}_{3} \mathrm{~N}_{2} \mathrm{O}_{1}[\mathrm{M}]^{+}$, 280.25. Found 281.<smiles>Cn1ccnc1C(=O)/C=C/c1ccco1</smiles>

(E)-3-(furan-2-yl)-1-(1-methyl-1H-imidazol-2-yl)prop-2-en-1-one

(16a): Prepared following general procedure (B), purified with $40 \%$ EtOAc/hexanes, to give $1.31 \mathrm{~g}(65 \%)$ of $\mathbf{1 6 a}$ as a yellow solid. $\mathrm{R} f=0.20$ (40\% EtOAc/hexanes); $\mathrm{mp}=79-80{ }^{\circ} \mathrm{C}$; IR (film) 3130, 1657, $1602 \mathrm{~cm}^{-1}$; 
${ }^{1} \mathrm{H}$ NMR $\left(500 \mathrm{MHz}, \mathrm{CDCl}_{3}\right) \delta 7.92(\mathrm{~d}, J=16.0 \mathrm{~Hz}, 1 \mathrm{H}), 7.59(\mathrm{~d}, J=16.0 \mathrm{~Hz}, 1 \mathrm{H}), 7.51(\mathrm{~s}, 1 \mathrm{H})$, $7.20(\mathrm{~s}, 1 \mathrm{H}), 7.07(\mathrm{~s}, 1 \mathrm{H}), 6.73(\mathrm{~d}, J=3.0 \mathrm{~Hz}, 1 \mathrm{H}), 6.49(\mathrm{br} \mathrm{s}, 1 \mathrm{H}), 4.07(\mathrm{~s}, 3 \mathrm{H}) ;{ }^{13} \mathrm{C}$ NMR $(125$ $\left.\mathrm{MHz}, \mathrm{CDCl}_{3}\right) \delta 180.2,151.8,144.9,143.9,129.3,129.2,127.1,120.7$ 115.6, 112.4, 36.18; LRMS (electrospray): Mass calculated for $\mathrm{C}_{11} \mathrm{H}_{10} \mathrm{~N}_{2} \mathrm{O}_{2}[\mathrm{M}]^{+}, 202.21$. Found 203.

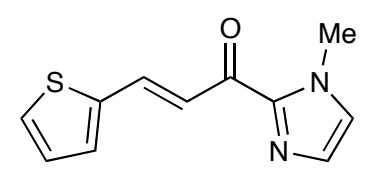

(E)-1-(1-methyl-1H-imidazol-2-yl)-3-(thiophen-2-yl)prop-2-en-1-one

(17a): Prepared following general procedure (B), purified with $40 \%$

EtOAc/hexanes, to give $1.38 \mathrm{~g}(63 \%)$ of $\mathbf{1 7 a}$ as a yellow solid. $\mathrm{R} f=0.20$ (40\% EtOAc/hexanes); $\mathrm{mp}=103-105^{\circ} \mathrm{C}$; IR (film) 3128, 3014, 1655, $1596 \mathrm{~cm}^{-1} ;{ }^{1} \mathrm{H}$ NMR $\left(500 \mathrm{MHz}, \mathrm{CDCl}_{3}\right) \delta 7.95(\mathrm{~d}, J=15.5 \mathrm{~Hz}, 1 \mathrm{H}), 7.84(\mathrm{~d}, J=15.5 \mathrm{~Hz}, 1 \mathrm{H})$, $7.41(\mathrm{~d}, J=5.0 \mathrm{~Hz}, 1 \mathrm{H}), 7.37(\mathrm{~d}, J=3.0 \mathrm{~Hz}, 1 \mathrm{H}), 7.21(\mathrm{~s}, 1 \mathrm{H}), 7.20(\mathrm{~s}, 1 \mathrm{H}), 7.07-7.06(\mathrm{~m}, 2 \mathrm{H})$, 4.07 (s, 3H); ${ }^{13} \mathrm{C}$ NMR $\left(125 \mathrm{MHz}, \mathrm{CDCl}_{3}\right) \delta$ 180.0, 143.8, 140.4, 135.7, 131.8, 129.2, 129.0, 128.1, 127.1, 121.6, 36.2; LRMS (electrospray): Mass calculated for $\mathrm{C}_{11} \mathrm{H}_{10} \mathrm{~N}_{2} \mathrm{OS}[\mathrm{M}]^{+}, 218.27$. Found 219.

\section{General Procedure C for Converting $\alpha$-Keto Acids to the Sodium Carboxylate Salts}

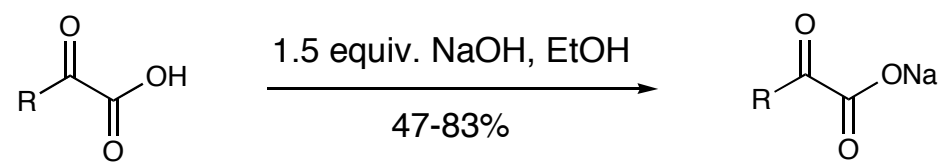

\begin{tabular}{ccc}
\hline $\mathrm{R}$ & Time $(\mathrm{min})$ & Yield (\%) \\
\hline propyl & 60 & 83 \\
phenyl & 45 & 78 \\
furyl & 15 & 72 \\
thiophene & 60 & 54 \\
1-Me-imidazole & 45 & 81 \\
4-butene & 15 & 47 \\
$\mathrm{CF}_{3}$ & 30 & 76 \\
\hline
\end{tabular}

The carboxylate salts sodium pyrvuate and sodium 4-methyl-2-oxopentanate are commercially available. Commercially available $\alpha$-keto acids (2-oxopentanoic acid; oxo(phenyl)acetic acid; 2-furyl(oxo)acetic acid; oxo(2-thienyl)acetic acid) were converted to the corresponding sodium carboxylate salts.

The $\alpha$-keto acid ( $10.0 \mathrm{mmol}, 1.0$ equiv) was added to a $100 \mathrm{~mL}$ RBF followed by EtOH (20 $\mathrm{mL}$ ). The solution was stirred at $23{ }^{\circ} \mathrm{C}$, and finely ground $\mathrm{NaOH}(600 \mathrm{mg}, 15.0 \mathrm{mmol}, 1.5$ equiv) was added in one portion to the reaction flask. The solution was stirred for the allotted time and the sodium carboxylate precipitated from the reaction solution. The resulting solid was filtered, washed with $\mathrm{EtOH}(50 \mathrm{~mL})$ and $\mathrm{Et}_{2} \mathrm{O}(50 \mathrm{~mL})$, and dried under vacuum. The sodium 
carboxylate salts were used without further purification.<smiles>Cn1ccnc1C(=O)C(=O)O</smiles>

Sodium-2-(1-methyl-1 $\boldsymbol{H}$-imidazol-2-yl)-2-oxoacetate was prepared in four steps starting from the procedure of Mosher and co-workers. ${ }^{5}{ }^{1} \mathrm{H}$ NMR (500 $\left.\mathrm{MHz}, \mathrm{D}_{2} \mathrm{O}\right) \delta 7.43(\mathrm{~s}, 1 \mathrm{H}), 7.24(\mathrm{~s}, 1 \mathrm{H}), 4.03$ (s, 3H); LRMS (electrospray): Mass calculated for $\mathrm{C}_{6} \mathrm{H}_{5} \mathrm{~N}_{2} \mathrm{O}_{3}[\mathrm{M}]^{-}, 153.03$. Found 153.<smiles>C=CCCC(=O)C(=O)O[Na]</smiles>

Sodium-2-oxohex-5-enoate was prepared in three steps starting from diethyl oxalate. ${ }^{6,7}{ }^{1} \mathrm{H}$ NMR $\left(500 \mathrm{MHz}, \mathrm{D}_{2} \mathrm{O}\right) \delta 5.96-5.88(\mathrm{~m}, 1 \mathrm{H}), 5.13-$ $5.05(\mathrm{~m}, 2 \mathrm{H}), 2.90(\mathrm{t}, J=7.0 \mathrm{~Hz}, 2 \mathrm{H}) 2.41-2.36(\mathrm{~m}, 2 \mathrm{H}) ;{ }^{13} \mathrm{C} \mathrm{NMR}(125$ $\mathrm{MHz}, \mathrm{D}_{2} \mathrm{O}$ ), (Note: The ketone peak was set as the reference peak at $\left.\delta 207.0\right) \delta 207.0,170.8$, 137.4, 115.6, 38.4, 27.0; LRMS (electrospray): Mass calculated for $\mathrm{C}_{6} \mathrm{H}_{7} \mathrm{O}_{3}[\mathrm{M}]$, 127.04. Found 127.<smiles>COC(=O)C(=O)C(F)(F)F</smiles>
Sodium 3,3,3-trifluoro-2-oxopropanoate was prepared in two steps starting from methyl 3,3,3-trifluoropyruvate. ${ }^{13} \mathrm{C}$ NMR $\left(125 \mathrm{MHz}, \mathrm{D}_{2} \mathrm{O}\right)$, (Note: residual EtOH served as an internal standard for the ${ }^{13} \mathrm{C}$ NMR peaks) $\delta 175.7,172.0$, 126.3, 124.0, 121.7, 119.4; LRMS (electrospray): Mass calculated for $\mathrm{C}_{3} \mathrm{~F}_{3} \mathrm{O}_{3}$ [M]', 140.98 . Found 141; Mass calculated for $\mathrm{C}_{3} \mathrm{~F}_{3} \mathrm{O}_{3}-\mathrm{H}_{2} \mathrm{O}$ [M] (hydrated compound), 158.99. Found 159 .

\section{General Procedure D for Thiazolium Catalyzed $\alpha$-keto acid Additions}

A screw-capped tube was charged with 3-benzyl-5-(2-hydroxyethyl)-4-methyl-thiazolium chloride (5) (thiazole carbene precursor) (22 $\mathrm{mg}, 0.08 \mathrm{mmol}, 20 \mathrm{~mol} \%$ ), $\alpha$-keto carboxylate sodium salt ( $0.72 \mathrm{mmol}, 1.8$ equiv), and $\alpha, \beta$-unsaturated-keto- $N$-methylimidazole substrate $(0.40$ mmol, 1.0 equiv) on the benchtop. Next, $\mathrm{MeOH}(450 \mu \mathrm{L})$ and $\mathrm{pH} 7.2$ phosphate buffer $(350 \mu \mathrm{L}$, $100 \mathrm{mM}$,) were added via syringe to the screw-capped tube. The resulting mixture was heated to $70{ }^{\circ} \mathrm{C}$ and allowed to stir for the allotted time ( $8 \mathrm{~h}$ to $24 \mathrm{~h}$ ). Upon completion of the reaction (as judged by TLC, $90 \%$ ether/hexanes), the reaction was cooled to room temperature, diluted with

\footnotetext{
5 Nimitz, J. S.; Mosher, H. S. J. Org. Chem. 1981, 46, 211-213.

${ }^{6}$ Weinstock, L. M.; Currie, R. B.; Lovell, A. V. Synth. Commun. 1981, 11, 943-946.

7 Imoto, H.; Imamiya, E.; Momose, Y.; Sugiyama, Y.; Kimura, H.; Sohda, T. Chem. Pharm. Bull. 2002, 50, 13491357.
} 
EtOAc $(10 \mathrm{~mL})$ and transferred to a separatory funnel. Saturated $\mathrm{NaCl}(10 \mathrm{~mL})$, saturated $\mathrm{NaHCO}_{3}(10 \mathrm{~mL})$, and $\mathrm{H}_{2} \mathrm{O}(10 \mathrm{ml})$ were added and the aqueous layer was extracted with EtOAc $(3 \times 40 \mathrm{~mL})$. The combined organic extracts were dried over sodium sulfate, filtered, and concentrated on a rotary evaporator. The resulting residue was purified by flash column chromatography on silica gel. Note: Reactions that were conducted under non-aqueous conditions (MeOH only) using DBU employed N-methyl-4,5-dimethylthiazolium iodide as the catalyst.

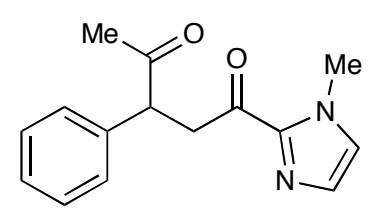

1-(1-methyl-1 $H$-imidazol-2-yl)-3-phenylpentane-1, 4 - d i o n e (7): Purified with $40 \%$ EtOAc/hexanes, to give $94 \mathrm{mg}(92 \%)$ of 7 as an offwhite solid. $\mathrm{R} f=0.35$ (90\% ether/hexanes); $\mathrm{mp}=72-74{ }^{\circ} \mathrm{C}$; IR (film) 3107, 3028, 2959, 1715, $1677 \mathrm{~cm}^{-1} ;{ }^{1} \mathrm{H}$ NMR (500 MHz, $\left.\mathrm{CDCl}_{3}\right) \delta 7.25-$ $7.21(\mathrm{~m}, 5 \mathrm{H}), 7.19(\mathrm{~s}, 1 \mathrm{H}), 7.05(\mathrm{~s}, 1 \mathrm{H}), 4.26(\mathrm{dd}, J=10.3,3.5 \mathrm{~Hz}, 1 \mathrm{H})$, $4.09(\mathrm{dd}, J=18.3,10.0 \mathrm{~Hz}, 1 \mathrm{H}), 3.89(\mathrm{~s}, 3 \mathrm{H}), 3.26(\mathrm{dd}, J=18.5,3.5 \mathrm{~Hz}, 1 \mathrm{H}), 2.11(\mathrm{~s}, 3 \mathrm{H}) ;{ }^{13} \mathrm{C}$ NMR $\left(125 \mathrm{MHz}, \mathrm{CDCl}_{3}\right) \delta$ 207.3, 190.8, 142.8, 138.0, 129.4, 129.2, 128.6, 127.8, 127.1, 54.1, 42.5, 36.3, 29.2; LRMS (electrospray): Mass calculated for $\mathrm{C}_{15} \mathrm{H}_{16} \mathrm{~N}_{2} \mathrm{O}_{2}[\mathrm{M}]^{+}, 256.30$. Found 257.

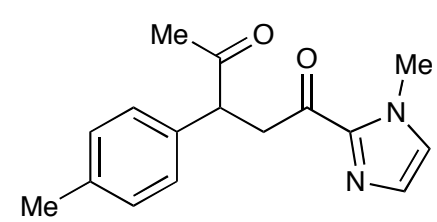

1-(1-methyl-1H-imidazol-2-yl)-3-p-tolylpentane-1,4-dione (8): Purified with $45 \%$ EtOAc/hexanes, to give $94 \mathrm{mg}(87 \%)$ of $\mathbf{8}$ as a white solid. $\mathrm{R} f=0.34$ (90\% ether/hexanes); $\mathrm{mp}=125-127{ }^{\circ} \mathrm{C}$; IR (film) $3002,1713,1674 \mathrm{~cm}^{-1} ;{ }^{1} \mathrm{H}$ NMR $\left(500 \mathrm{MHz}, \mathrm{CDCl}_{3}\right) \delta 7.14-$ $7.09(\mathrm{~m}, 5 \mathrm{H}), 7.08(\mathrm{~s}, 1 \mathrm{H}), 6.97(\mathrm{~s}, 1 \mathrm{H}), 4.27(\mathrm{dd}, J=10.0,3.5 \mathrm{~Hz}$, $1 \mathrm{H}), 4.11$ (dd, $J=18.3,10.0 \mathrm{~Hz}, 1 \mathrm{H}), 3.92$ (s, 3H), 3.27 (dd, $J=18.0,4.0 \mathrm{~Hz}, 1 \mathrm{H}), 2.29$ (s, 3H), 2.13 (s, 3H); ${ }^{13} \mathrm{C}$ NMR $\left(125 \mathrm{MHz}, \mathrm{CDCl}_{3}\right) \delta$ 207.2, 190.7, 142.6, 137.2, 134.7, 129.7, 129.1, 128.3, 126.8, 53.5, 42.2, 36.0, 28.8, 21.0; LRMS (electrospray): Mass calculated for $\mathrm{C}_{16} \mathrm{H}_{18} \mathrm{~N}_{2} \mathrm{O}_{2}$ $[\mathrm{M}]^{+}, 270.33$. Found 271.<smiles>COc1ccc(C(CC(=O)c2nccn2C)C(C)=O)cc1</smiles>

3-(4-methoxyphenyl)-1-(1-methyl-1H-imidazol-2-yl)pentane-1,4dione (9): Purified with 35\% EtOAc/hexanes, to give $93 \mathrm{mg}(81 \%)$ of 9 as a white solid. $\mathrm{R} f=0.30$ (90\% ether/hexanes); $\mathrm{mp}=107-109$ ${ }^{\circ} \mathrm{C}$; IR (film) 2957, 2932, 1712, $1675 \mathrm{~cm}^{-1}$; ${ }^{1} \mathrm{H}$ NMR $(500 \mathrm{MHz}$, $\left.\mathrm{CDCl}_{3}\right) \delta 7.15(\mathrm{~d}, J=8.5 \mathrm{~Hz}, 2 \mathrm{H}), 7.08(\mathrm{~s}, 1 \mathrm{H}), 6.97(\mathrm{~s}, 1 \mathrm{H}), 6.82$ $(\mathrm{d}, J=8.5 \mathrm{~Hz}, 2 \mathrm{H}), 4.24(\mathrm{dd}, J=10.0,3.5 \mathrm{~Hz}, 1 \mathrm{H}), 4.08(\mathrm{dd}, J=18.3,10.0 \mathrm{~Hz}, 1 \mathrm{H}), 3.91$ (s, $3 \mathrm{H}), 3.75(\mathrm{~s}, 3 \mathrm{H}), 3.27(\mathrm{dd}, J=18.0,4.0 \mathrm{~Hz}, 1 \mathrm{H}), 2.13(\mathrm{~s}, 3 \mathrm{H}) ;{ }^{13} \mathrm{C} \mathrm{NMR}\left(125 \mathrm{MHz}, \mathrm{CDCl}_{3}\right) \delta$ 207.3, 190.7, 158.9, 142.6, 129.7, 129.4, 129.1, 126.8, 114.3, 55.2, 53.0, 42.3, 36.0, 28.8; LRMS (electrospray): Mass calculated for $\mathrm{C}_{16} \mathrm{H}_{18} \mathrm{~N}_{2} \mathrm{O}_{3}[\mathrm{M}]^{+}, 286.33$. Found 287. 


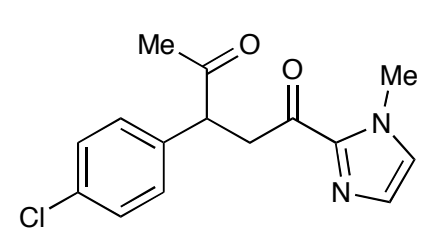

\section{3-(4-chlorophenyl)-1-(1-methyl-1H-imidazol-2-yl)pentane-1,4-}

dione (10): Purified with 40\% EtOAc/hexanes, to give $102 \mathrm{mg}(87 \%)$ of 10 as a white solid. $\mathrm{R} f=0.30(90 \%$ ether/hexanes); $\mathrm{mp}=108-110$ ${ }^{\circ} \mathrm{C}$; IR (film) 3119, 2957, 1715, $1676 \mathrm{~cm}^{-1}$; ${ }^{1} \mathrm{H}$ NMR $(500 \mathrm{MHz}$, $\left.\mathrm{CDCl}_{3}\right) \delta 7.22(\mathrm{~d}, J=8.0 \mathrm{~Hz}, 2 \mathrm{H}), 7.14(\mathrm{~d}, J=8.0 \mathrm{~Hz}, 2 \mathrm{H}) 7.03(\mathrm{~s}$,

$1 \mathrm{H}), 6.94(\mathrm{~s}, 1 \mathrm{H}), 4.23(\mathrm{dd}, J=10.0,4.0 \mathrm{~Hz}, 1 \mathrm{H}), 4.02(\mathrm{dd}, J=18.5,10.5 \mathrm{~Hz}, 1 \mathrm{H}), 3.87(\mathrm{~s}, 3 \mathrm{H})$, $3.26(\mathrm{dd}, J=18.5,4.0 \mathrm{~Hz}, 1 \mathrm{H}), 2.09$ (s, 3H); ${ }^{13} \mathrm{C} \mathrm{NMR}\left(125 \mathrm{MHz}, \mathrm{CDCl}_{3}\right) \delta 206.4,190.1,142.4$, 136.2, 133.4, 129.6, 129.1, 129.1, 126.9, 53.1, 42.1, 35.9, 28.9; LRMS (electrospray): Mass calculated for $\mathrm{C}_{15} \mathrm{H}_{15} \mathrm{ClN}_{2} \mathrm{O}_{2}[\mathrm{M}]^{+}, 290.74$. Found 291 .

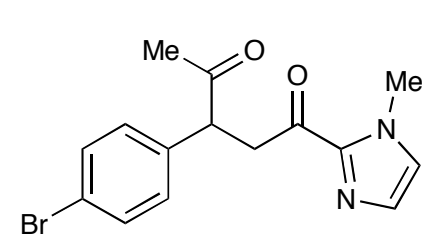

\section{3-(4-methoxyphenyl)-1-(1-methyl-1H-imidazol-2-yl)pentane-1,4-}

dione (11): Purified with 40\% EtOAc/hexanes, to give $95 \mathrm{mg}(71 \%)$ of 11 as a white solid. $\mathrm{R} f=0.25$ (90\% ether/hexanes); $\mathrm{mp}=119-120$ ${ }^{\circ} \mathrm{C}$; IR (film) 3110, 2958, 1714, $1675 \mathrm{~cm}^{-1}$; ${ }^{1} \mathrm{H}$ NMR $(500 \mathrm{MHz}$, $\left.\mathrm{CDCl}_{3}\right) \delta 7.42(\mathrm{~d}, J=8.0 \mathrm{~Hz}, 2 \mathrm{H}), 7.13(\mathrm{~d}, J=8.0 \mathrm{~Hz}, 2 \mathrm{H}) 7.09$ (s, $1 \mathrm{H}), 6.99(\mathrm{~s}, 1 \mathrm{H}), 4.27$ (dd, $J=10.0,3.5 \mathrm{~Hz}, 1 \mathrm{H}), 4.07$ (dd, $J=18.0,10.0 \mathrm{~Hz}, 1 \mathrm{H}), 3.92(\mathrm{~s}, 3 \mathrm{H})$, $3.31(\mathrm{dd}, J=18.0,4.0 \mathrm{~Hz}, 1 \mathrm{H}), 2.14(\mathrm{~s}, 3 \mathrm{H}) ;{ }^{13} \mathrm{C} \mathrm{NMR}\left(125 \mathrm{MHz}, \mathrm{CDCl}_{3}\right) \delta 206.4,190.1,142.4$, 136.7, 132.0, 130.0, 129.2, 126.9, 121.5, 53.2, 42.0, 35.9, 28.9; LRMS (electrospray): Mass calculated for $\mathrm{C}_{15} \mathrm{H}_{15} \mathrm{BrN}_{2} \mathrm{O}_{2}[\mathrm{M}]^{+}, 335.20$. Found 336 .

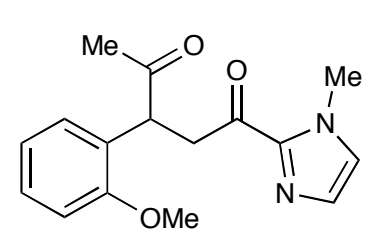

3-(2-methoxyphenyl)-1-(1-methyl-1H-imidazol-2-yl)pentane-1,4-

dione (12): Purified with 45\% EtOAc/hexanes, to give $99 \mathrm{mg}(87 \%)$ of 12 as a colorless oil. $\mathrm{R} f=0.25$ (90\% ether/hexanes); IR (film) 3109, 3003, 2957, 2837, 1716, $1680 \mathrm{~cm}^{-1} ;{ }^{1} \mathrm{H} \mathrm{NMR}\left(500 \mathrm{MHz}, \mathrm{CDCl}_{3}\right) \delta 7.15$ $(\mathrm{t}, J=9.0 \mathrm{~Hz}, 1 \mathrm{H}), 7.03(\mathrm{~s}, 1 \mathrm{H}), 6.93(\mathrm{~s}, 1 \mathrm{H}) 6.78(\mathrm{~d}, J=7.5 \mathrm{~Hz}, 1 \mathrm{H})$, $6.72(\mathrm{~m}, 2 \mathrm{H}), 4.22(\mathrm{dd}, J=10.0,2.5 \mathrm{~Hz}, 1 \mathrm{H}), 4.07(\mathrm{dd}, J=18.2,10.5 \mathrm{~Hz}$, $1 \mathrm{H}), 3.87(\mathrm{~s}, 3 \mathrm{H}), 3.70(\mathrm{~s}, 3 \mathrm{H}), 3.24(\mathrm{dd}, J=18.0,3.0 \mathrm{~Hz}, 1 \mathrm{H}), 2.10(\mathrm{~s}, 3 \mathrm{H}) ;{ }^{13} \mathrm{C}$ NMR $(125$ $\left.\mathrm{MHz}, \mathrm{CDCl}_{3}\right) \delta$ 206.8, 190.4, 159.9, 142.4, 139.1, 129.9, 129.0, 126.8, 120.7, 113.6, 113.00, 55.1, 53.8, 42.0, 35.9, 28.8; LRMS (electrospray): Mass calculated for $\mathrm{C}_{16} \mathrm{H}_{18} \mathrm{~N}_{2} \mathrm{O}_{3}[\mathrm{M}]^{+}, 286.33$. Found 287.

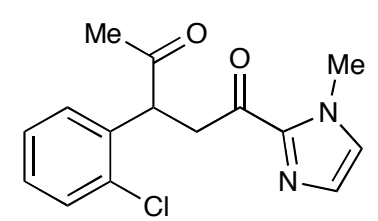

\section{3-(2-chlorophenyl)-1-(1-methyl-1H-imidazol-2-yl)pentane-1,4-}

dione (13): Purified with 45\% EtOAc/hexanes, to give $111 \mathrm{mg}(95 \%)$ of 13 as a colorless oil. $\mathrm{R} f=0.25$ (90\% ether/hexanes); IR (film) 3110 , 2957, 2922, 1723, $1680 \mathrm{~cm}^{-1} ;{ }^{1} \mathrm{H} \operatorname{NMR}\left(500 \mathrm{MHz}, \mathrm{CDCl}_{3}\right) \delta 7.3(\mathrm{~m}, 1 \mathrm{H})$, $7.13(\mathrm{~m}, 3 \mathrm{H}), 7.02(\mathrm{~s}, 1 \mathrm{H}) 6.94(\mathrm{~s}, 1 \mathrm{H}), 4.83(\mathrm{dd}, J=10.0,3.0 \mathrm{~Hz}, 1 \mathrm{H})$, $4.04(\mathrm{dd}, J=18.5,10.0 \mathrm{~Hz}, 1 \mathrm{H}), 3.87(\mathrm{~s}, 3 \mathrm{H}), 3.19(\mathrm{dd}, J=18.5,3.5 \mathrm{~Hz}, 1 \mathrm{H}), 2.10(\mathrm{~s}, 3 \mathrm{H}) ;{ }^{13} \mathrm{C}$ NMR (125 MHz, $\left.\mathrm{CDCl}_{3}\right) \delta$ 206.1, 189.8, 142.3, 135.4, 133.8, 129.9, 129.1, 129.0, 128.6, 127.3, 126.8, 49.5, 41.1, 35.8, 29.0; LRMS (electrospray): Mass calculated for $\mathrm{C}_{15} \mathrm{H}_{15} \mathrm{ClN}_{2} \mathrm{O}_{2}[\mathrm{M}]^{+}$, 290.74. Found 291. 


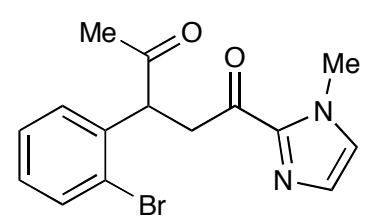

3-(2-bromophenyl)-1-(1-methyl-1H-imidazol-2-yl)pentane-1,4-dione (14): Purified with $45 \%$ EtOAc/hexanes, to give $120 \mathrm{mg}(89 \%)$ of 14 as a colorless oil. $\mathrm{R} f=0.25$ (90\% ether/hexanes); IR (film) 3110,2957 , 2921, 1739, $1676 \mathrm{~cm}^{-1} ;{ }^{1} \mathrm{H} \mathrm{NMR}\left(500 \mathrm{MHz}, \mathrm{CDCl}_{3}\right) \delta 7.52(\mathrm{~d}, J=8.5$ $\mathrm{Hz}, 1 \mathrm{H}), 7.18(\mathrm{t}, J=7.0 \mathrm{~Hz}, 1 \mathrm{H}), 7.10(\mathrm{~d}, J=7.5 \mathrm{~Hz}, 1 \mathrm{H}), 7.05(\mathrm{~m}, 2 \mathrm{H})$, $7.02(\mathrm{~s}, 1 \mathrm{H}) 6.94(\mathrm{~s}, 1 \mathrm{H}), 4.84(\mathrm{dd}, J=10.0,2.5 \mathrm{~Hz}, 1 \mathrm{H}), 4.03(\mathrm{dd}, J=18.5,10.5 \mathrm{~Hz}, 1 \mathrm{H}), 3.88$ $(\mathrm{s}, 3 \mathrm{H}), 3.18(\mathrm{dd}, J=18.5,3.0 \mathrm{~Hz}, 1 \mathrm{H}), 2.11(\mathrm{~s}, 3 \mathrm{H}) ;{ }^{13} \mathrm{C} \mathrm{NMR}\left(125 \mathrm{MHz}, \mathrm{CDCl}_{3}\right) \delta 206.1$, $189.8,142.3$, 137.1, 133.3, 129.1, 129.0, 128.9, 127.9, 126.8, 124.8, 52.1, 41.3, 35.9, 29.1; LRMS (electrospray): Mass calculated for $\mathrm{C}_{15} \mathrm{H}_{15} \mathrm{BrN}_{2} \mathrm{O}_{2}[\mathrm{M}]^{+}, 335.2$. Found 336.

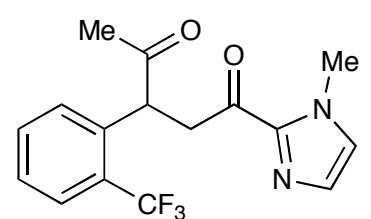

3-(2-(trifluoromethyl)phenyl)-1-(1-methyl-1H-imidazol-2-yl)pentane-

1,4-dione (15): Purified with 45\% EtOAc/hexanes, to give $99 \mathrm{mg}(76 \%)$ as a tan oil. $\mathrm{R} f=0.33$ (90\% ether/hexanes); IR (film) 3112, 2961, 2925, $1718,1676 \mathrm{~cm}^{-1} ;{ }^{1} \mathrm{H}$ NMR $\left(500 \mathrm{MHz}, \mathrm{CDCl}_{3}\right) \delta 7.71(\mathrm{~d}, J=7.5 \mathrm{~Hz}, 1 \mathrm{H})$, $7.50(\mathrm{t}, J=7.5 \mathrm{~Hz}, 1 \mathrm{H}), 7.38(\mathrm{t}, J=7.5 \mathrm{~Hz}, 1 \mathrm{H}), 7.33(\mathrm{~d}, J=8.0 \mathrm{~Hz} 2 \mathrm{H})$, $7.10(\mathrm{~s}, 1 \mathrm{H}) 7.02(\mathrm{~s}, 1 \mathrm{H}), 4.77(\mathrm{dd}, J=10.5,2.5 \mathrm{~Hz}, 1 \mathrm{H}), 4.03(\mathrm{dd}, J=18.5,10.5 \mathrm{~Hz}, 1 \mathrm{H}), 3.97$ $(\mathrm{s}, 3 \mathrm{H}), 3.20(\mathrm{dd}, J=18.5,2.5 \mathrm{~Hz}, 1 \mathrm{H}), 2.17(\mathrm{~s}, 3 \mathrm{H}) ;{ }^{13} \mathrm{C} \mathrm{NMR}\left(125 \mathrm{MHz}, \mathrm{CDCl}_{3}\right) \delta 206.1$, 189.6, 142.1, 136.2, 132.3, 129.6, 129.4, 129.1, 128.8, 127.5, 126.9, 126.4, 48.5, 43.0, 36.0, 29.1; LRMS (electrospray): Mass calculated for $\mathrm{C}_{16} \mathrm{H}_{15} \mathrm{~F}_{3} \mathrm{~N}_{2} \mathrm{O}_{2}[\mathrm{M}]^{+}, 324.30$. Found 325.

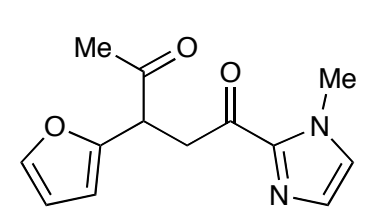

3-(furan-2-yl)-1-(1-methyl-1 $H$-imidazol-2-yl)pentane-1,4-dione (16): Purified with 50\% EtOAc/hexanes, to give $79 \mathrm{mg}(80 \%)$ of 16 as a tan oil. $\mathrm{R} f=0.25$ (90\% ether/hexanes); IR (film) $3114,1719,1675 \mathrm{~cm}^{-1} ;{ }^{1} \mathrm{H}$ NMR $\left(500 \mathrm{MHz}, \mathrm{CDCl}_{3}\right) \delta 7.36$ (br s, 1H), $7.13(\mathrm{~s}, 1 \mathrm{H}), 7.04(\mathrm{~s}, 1 \mathrm{H}), 6.33$ (br s, $1 \mathrm{H}), 6.22$ (br d, $J=2.0 \mathrm{~Hz}, 1 \mathrm{H}), 4.45$ (dd, $J=10.0,4.0 \mathrm{~Hz}, 1 \mathrm{H}), 4.09$ (dd, $J=18.5,10.0 \mathrm{~Hz}, 1 \mathrm{H}), 3.95(\mathrm{~s}, 3 \mathrm{H}), 3.44(\mathrm{dd}, J=18.0,4.0 \mathrm{~Hz}, 1 \mathrm{H}), 2.25(\mathrm{~s}, 3 \mathrm{H}) ;{ }^{13} \mathrm{C}$ NMR $(125$ $\left.\mathrm{MHz}, \mathrm{CDCl}_{3}\right) \delta 204.5,189.7,151.1,142.3,142.2,129.1,126.9,110.6,107.2,47.1,39.3,35.9$, 28.7; LRMS (electrospray): Mass calculated for $\mathrm{C}_{13} \mathrm{H}_{14} \mathrm{~N}_{2} \mathrm{O}_{3}[\mathrm{M}]^{+}, 246.26$. Found 247.

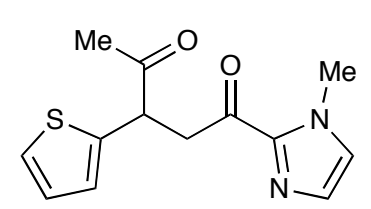

\section{1-(1-methyl-1H-imidazol-2-yl)-3-(thiophen-2-yl)pentane-1,4-dione}

(17): Purified with 50\% EtOAc/hexanes, to give $95 \mathrm{mg}(90 \%)$ of 17 as a tan oil. $\mathrm{R} f=0.30$ (90\% ether/hexanes); IR (film) 3107, 2920, 1717, 1674 $\mathrm{cm}^{-1} ;{ }^{1} \mathrm{H}$ NMR $\left(500 \mathrm{MHz}, \mathrm{CDCl}_{3}\right) \delta 7.22(\mathrm{~m}, 1 \mathrm{H}), 7.21(\mathrm{~s}, 1 \mathrm{H}), 7.12(\mathrm{~s}$, $1 \mathrm{H}), 7.02(\mathrm{~m}, 2 \mathrm{H}), 4.60(\mathrm{dd}, J=10.0,4.0 \mathrm{~Hz}, 1 \mathrm{H}), 4.15(\mathrm{dd}, J=18.5$, $10.0 \mathrm{~Hz}, 1 \mathrm{H}), 3.95(\mathrm{~s}, 3 \mathrm{H}), 3.46(\mathrm{dd}, J=18.0,3.5 \mathrm{~Hz}, 1 \mathrm{H}), 2.26(\mathrm{~s}, 3 \mathrm{H}) ;{ }^{13} \mathrm{C} \mathrm{NMR}(125 \mathrm{MHz}$, $\left.\mathrm{CDCl}_{3}\right) \delta 204.5,189.7,151.1,142.3,142.2,129.1,126.9,110.6,107.2,47.1,39.3,35.9,28.7$; LRMS (electrospray): Mass calculated for $\mathrm{C}_{13} \mathrm{H}_{14} \mathrm{~N}_{2} \mathrm{O}_{2} \mathrm{~S}[\mathrm{M}]^{+}, 262.33$. Found 263.

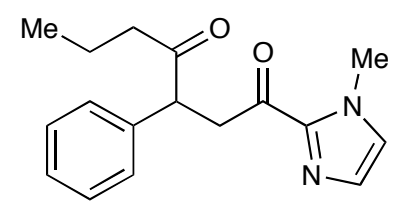

1-(1-methyl-1H-imidazol-2-yl)-3-phenylheptane-1,4-dione (18): Purified with $35 \%$ EtOAc/hexanes, to give $104 \mathrm{mg}(92 \%)$ of 18 as a colorless oil. $\mathrm{R} f=0.45$ (90\% ether/hexanes); IR (film) 2955, 2933, 2875, 1721, $1676 \mathrm{~cm}^{-1} ;{ }^{1} \mathrm{H}$ NMR $\left(500 \mathrm{MHz}, \mathrm{CDCl}_{3}\right) \delta 7.24-7.17(\mathrm{~m}$, $5 \mathrm{H}), 7.01(\mathrm{~s}, 1 \mathrm{H}), 6.91(\mathrm{~s}, 1 \mathrm{H}), 4.24(\mathrm{dd}, J=10.8,3.5 \mathrm{~Hz}, 1 \mathrm{H}), 4.10(\mathrm{dd}$, $J=18.0,10.5 \mathrm{~Hz}, 1 \mathrm{H}), 3.85(\mathrm{~s}, 3 \mathrm{H}), 3.22(\mathrm{dd}, J=18.3,3.5 \mathrm{~Hz}, 1 \mathrm{H}), 2.49-2.42(\mathrm{~m}, 1 \mathrm{H}) 2.36-2.30$ $(\mathrm{m}, 1 \mathrm{H}), 1.52-1.48(\mathrm{~m}, 1 \mathrm{H}), 1.45-1.41(\mathrm{~m}, 1 \mathrm{H}), 0.71(\mathrm{t}, J=7.5 \mathrm{~Hz}, 3 \mathrm{H}) ;{ }^{13} \mathrm{C} \mathrm{NMR}(125 \mathrm{MHz}$, $\left.\mathrm{CDCl}_{3}\right) \delta 209.0,190.5,142.5,137.8,129.0,129.0,128.8,128.6,128.3,127.3,126.7,53.2,43.3$, 
42.2, 35.9, 16.9, 13.4; LRMS (electrospray): Mass calculated for $\mathrm{C}_{17} \mathrm{H}_{20} \mathrm{~N}_{2} \mathrm{O}_{2}[\mathrm{M}]^{+}, 284.35$. Found 285.

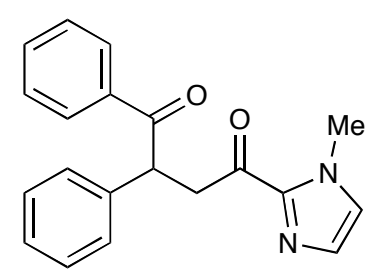

4-(1-methyl-1H-imidazol-2-yl)-1,2-diphenylbutane-1,4-dione (19): The synthesis of 19 employed a thiazolium catalyst (20 mol\%), DBU (7 $\mu \mathrm{L}, 0.056 \mathrm{mmol}, 14 \%)$, and $\mathrm{MeOH}(750 \mu \mathrm{L})$ under non-aqueous conditions, $18 \mathrm{~h}$ at $70{ }^{\circ} \mathrm{C}$. Purified with $40 \%$ EtOAc/hexanes, to give 115 $\mathrm{mg}(90 \%)$ of 19 as an off-white solid. $\mathrm{R} f=0.40$ (90\% ether/hexanes); mp $=127-130{ }^{\circ} \mathrm{C}$; IR (film) 3060, 3028, 1674, $1411 \mathrm{~cm}^{-1} ;{ }^{1} \mathrm{H}$ NMR $(500$ $\left.\mathrm{MHz} \mathrm{CDCl}_{3}\right) \delta 8.03(\mathrm{~d}, J=7.5 \mathrm{~Hz}, 2 \mathrm{H}), 7.46(\mathrm{t}, J=7.5 \mathrm{~Hz} 1 \mathrm{H}), 7.39$ (t, $\left.J=7.5 \mathrm{~Hz}, 2 \mathrm{H}\right), 7.33$ $(\mathrm{d}, J=7.5 \mathrm{~Hz}, 2 \mathrm{H}), 7.27(\mathrm{t}, J=7.5 \mathrm{~Hz}, 2 \mathrm{H}), 7.19(\mathrm{t}, J=7.0 \mathrm{~Hz}, 1 \mathrm{H}), 7.13(\mathrm{~s}, 1 \mathrm{H}), 6.99(\mathrm{~s}, 1 \mathrm{H})$, $5.23(\mathrm{dd}, J=10.7,3.5 \mathrm{~Hz}, 1 \mathrm{H}), 4.37(\mathrm{dd}, J=18.7,10.5 \mathrm{~Hz}, 1 \mathrm{H}), 3.92$ (s, 3H), 3.49 (dd, $J=18.7$, $3.5 \mathrm{~Hz}, 1 \mathrm{H}) ;{ }^{13} \mathrm{C} \mathrm{NMR}\left(125 \mathrm{MHz}, \mathrm{CDCl}_{3}\right) \delta 198.7,190.5,142.5,138.3,136.4,132.8,129.2$, 129.0, 128.9, 128.5, 128.2, 127.2, 126.8, 48.5, 44.0, 36.0; LRMS (electrospray): Mass calculated for $\mathrm{C}_{20} \mathrm{H}_{18} \mathrm{~N}_{2} \mathrm{O}_{2}[\mathrm{M}]^{+}, 318.37$. Found 319 .

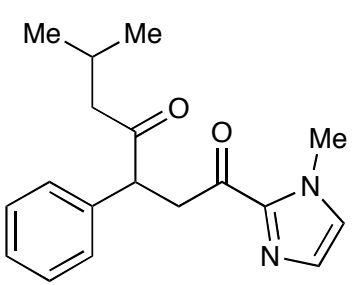

6-methyl-1-(1-methyl-1H-imidazole-2-yl)-3-phenylheptane-1,4-dione (20): Purified with 40\% EtOAc/hexanes, to give $86 \mathrm{mg}(72 \%)$ of 20 as an off-white solid. $\mathrm{R} f=0.41$ (90\% ether/hexanes); $\mathrm{mp}=78-79{ }^{\circ} \mathrm{C}$; IR (film) 2956, 2930, 2871, 1720, 1680, $\left.\mathrm{cm}^{-1} ;{ }^{1} \mathrm{H} \mathrm{NMR} \mathrm{(500} \mathrm{MHz,} \mathrm{CDCl}_{3}\right) \delta$ 7.33-7.25 (m, 5H), $7.11(\mathrm{~s}, 1 \mathrm{H}), 7.00(\mathrm{~s}, 1 \mathrm{H}), 4.30(\mathrm{dd}, J=10.5,3.5 \mathrm{~Hz}$, $1 \mathrm{H}), 4.19$ (dd, $J=18.0,10.5 \mathrm{~Hz}, 1 \mathrm{H}), 3.94(\mathrm{~s}, 3 \mathrm{H}), 3.29(\mathrm{dd}, J=18.0,3.5$ $\mathrm{Hz}, 1 \mathrm{H}), 2.46(\mathrm{dd}, J=16.5,6.0 \mathrm{~Hz}, 1 \mathrm{H}), 2.28(\mathrm{dd}, J=16.5,7.5 \mathrm{~Hz}, 1 \mathrm{H})$, 2.13 (sep, $J=7.0 \mathrm{~Hz}, 1 \mathrm{H}), 0.88(\mathrm{~d}, J=6.5 \mathrm{~Hz}, 3 \mathrm{H}), 0.72(\mathrm{~d}, J=6.5 \mathrm{~Hz}, 3 \mathrm{H}) ;{ }^{13} \mathrm{C}$ NMR $(125$ $\left.\mathrm{MHz}_{,} \mathrm{CDCl}_{3}\right) \delta 208.5,190.5,142.5,137.7,129.0,128.8,128.4,127.3,126.7,53.6,50.3,42.1$, 35.9, 24.0, 22.5, 22.1; LRMS (electrospray): Mass calculated for $\mathrm{C}_{18} \mathrm{H}_{22} \mathrm{~N}_{2} \mathrm{O}_{2}[\mathrm{M}]^{+}, 298.38$. Found 299.

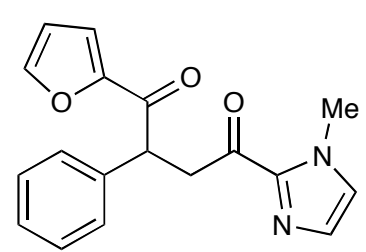

\section{1-(furan-2-yl)-4-(1-methyl-1 $H$-imidazol-2-yl)-2-phenylbutane-1,4}

dione (21): Purified with 40\% EtOAc/hexanes, to give $118 \mathrm{mg}(96 \%)$ of 21 as an off-white solid. $\mathrm{R} f=0.25$ (90\% ether/hexanes); $\mathrm{mp}=146-148$ ${ }^{\circ} \mathrm{C}$; IR (film) 3130, 1670, $1412 \mathrm{~cm}^{-1} ;{ }^{1} \mathrm{H}$ NMR (500 MHz, $\left.\mathrm{CDCl}_{3}\right) \delta 7.46$ $(\mathrm{s}, 1 \mathrm{H}), 7.30(\mathrm{~d}, J=7.0 \mathrm{~Hz}, 2 \mathrm{H}), 7.21(\mathrm{t}, J=7.0 \mathrm{~Hz}, 2 \mathrm{H}), 7.13(\mathrm{~m}, 2 \mathrm{H})$, $7.04(\mathrm{~s}, 1 \mathrm{H}), 6.92(\mathrm{~s}, 1 \mathrm{H}), 6.39(\mathrm{~m}, 1 \mathrm{H}), 4.93(\mathrm{dd}, J=10.2,3.5 \mathrm{~Hz}, 1 \mathrm{H})$, $4.24(\mathrm{dd}, J=18.8,10.5 \mathrm{~Hz}, 1 \mathrm{H}), 3.84(\mathrm{~s}, 3 \mathrm{H}), 3.46(\mathrm{dd}, J=18.3,3.5 \mathrm{~Hz}, 1 \mathrm{H}) ;{ }^{13} \mathrm{C}$ NMR $(125$ $\left.\mathrm{MHz}, \mathrm{CDCl}_{3}\right) \delta 190.2,187.5,152.0,146.3,142.4,137.8,129.1,128.7,128.3,127.2,126.8$, 117.9, 112.1, 48.4, 42.8, 35.9; LRMS (electrospray): Mass calculated for $\mathrm{C}_{18} \mathrm{H}_{16} \mathrm{~N}_{2} \mathrm{O}_{3}[\mathrm{M}]^{+}$, 308.33. Found 309.

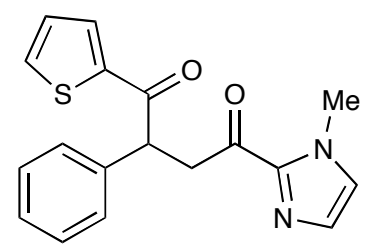

4-(1-methyl-1H-imidazol-2-yl)-2-phenyl-1-(thiophen-2-yl)butane-1,4 dione (22): (Note: $\mathrm{MeOH}(400 \mu \mathrm{L})$ and $\mathrm{pH} 7.2$ phosphate buffer $(200$ $\mu \mathrm{L})$ were used in the reaction). Purified with $40 \%$ EtOAc/hexanes, to give $99 \mathrm{mg}(76 \%)$ of 22 as a white solid. $\mathrm{R} f=0.30$ (90\% ether/hexanes); $\mathrm{mp}=177-181{ }^{\circ} \mathrm{C}$; IR (film) 3105, 1662, $1411 \mathrm{~cm}^{-1} ;{ }^{1} \mathrm{H}$ NMR $(500 \mathrm{MHz}$, $\left.\mathrm{CDCl}_{3}\right) \delta 7.72(\mathrm{~d}, J=4.0 \mathrm{~Hz}, 1 \mathrm{H}), 7.49(\mathrm{~d}, J=4.5 \mathrm{~Hz}, 1 \mathrm{H}), 7.30(\mathrm{~d}, J=$ 
$7.5 \mathrm{~Hz}, 2 \mathrm{H}), 7.22(\mathrm{t}, J=8.0 \mathrm{~Hz}, 2 \mathrm{H}), 7.14(\mathrm{t}, J=7.5 \mathrm{~Hz}, 1 \mathrm{H}), 7.06(\mathrm{~s}, 1 \mathrm{H}), 6.98(\mathrm{t}, J=4.5 \mathrm{~Hz}$, $1 \mathrm{H}), 6.93(\mathrm{~s}, 1 \mathrm{H}), 4.97(\mathrm{dd}, J=10.5,3.5 \mathrm{~Hz}, 1 \mathrm{H}), 4.27$ (dd, $J=18.2,10.5 \mathrm{~Hz}, 1 \mathrm{H}), 3.86(\mathrm{~s}, 3 \mathrm{H})$, $3.42(\mathrm{dd}, J=18.8,3.5 \mathrm{~Hz}, 1 \mathrm{H}) ;{ }^{13} \mathrm{C}$ NMR $\left(125 \mathrm{MHz}, \mathrm{CDCl}_{3}\right) \delta 191.5,190.2,143.4,142.5$, 138.4, 133.5, 132.7, 129.2, 128.9, 128.2, 128.0, 127.4, 126.9, 49.9, 43.6, 36.0; LRMS (electrospray): Mass calculated for $\mathrm{C}_{18} \mathrm{H}_{16} \mathrm{~N}_{2} \mathrm{O}_{3} \mathrm{~S}[\mathrm{M}]^{+}, 324.40$. Found 325 .

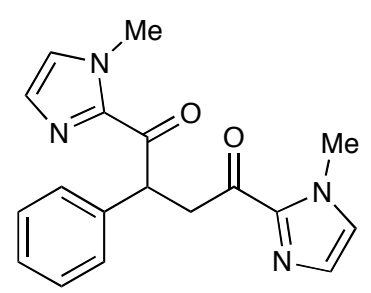

1,4-bis(1-methyl-1H-imidazol-2-yl)-2-phenylbutane-1,4-dione (23): The synthesis of $\mathbf{2 3}$ employed a thiazolium catalyst (20 mol\%), DBU ( 7 $\mu \mathrm{L}, 0.056 \mathrm{mmol}, 14 \%)$, and $\mathrm{MeOH}(750 \mu \mathrm{L})$ under non-aqueous conditions, $20 \mathrm{~h}$ at $70{ }^{\circ} \mathrm{C}$. Purified with $100 \%$ EtOAc, to give $117 \mathrm{mg}$ (91\%) of $\mathbf{2 3}$ as a white solid. $\mathrm{R} f=0.40(100 \% \mathrm{EtOAc}) ; \mathrm{mp}=154-155$ ${ }^{\circ} \mathrm{C}$; IR (film) 3107, 2957, 2918, 1670, $1406 \mathrm{~cm}^{-1}$; ${ }^{1} \mathrm{H}$ NMR $(500 \mathrm{MHz}$, $\left.\mathrm{CDCl}_{3}\right) \delta 7.49$ (d, $\left.J=7.5 \mathrm{~Hz}, 2 \mathrm{H}\right), 7.26(\mathrm{t}, J=7.5 \mathrm{~Hz} 2 \mathrm{H}), 7.18(\mathrm{t}, J=7.5 \mathrm{~Hz}, 1 \mathrm{H}), 7.15(\mathrm{~s}, 1 \mathrm{H})$, $7.11(\mathrm{~s}, 1 \mathrm{H}), 6.97(\mathrm{~s}, 1 \mathrm{H}), 6.94(\mathrm{~s}, 1 \mathrm{H}), 5.70(\mathrm{dd}, J=11.0,2.5 \mathrm{~Hz}, 1 \mathrm{H}), 4.30(\mathrm{dd}, J=18.5,11.0$ $\mathrm{Hz}, 1 \mathrm{H}), 3.90(\mathrm{br} \mathrm{s}, 6 \mathrm{H}), 3.64(\mathrm{dd}, J=18.5,3.0 \mathrm{~Hz}, 1 \mathrm{H}) ;{ }^{13} \mathrm{C} \mathrm{NMR}\left(125 \mathrm{MHz}, \mathrm{CDCl}_{3}\right) \delta 191.0$, 190.3, 142.4, 142.4, 138.0, 129.3, 129.0, 128.6, 128.5, 127.0, 126.7, 47.5, 42.8, 35.9, 35.9; LRMS (electrospray): Mass calculated for $\mathrm{C}_{18} \mathrm{H}_{18} \mathrm{~N}_{4} \mathrm{O}_{2}[\mathrm{M}]^{+}, 322.14$. Found 323.

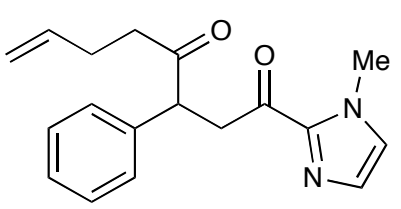

1-(1-methyl-1H-imidazol-2-yl)-3-phenyloct-7-ene-1,4-dione (24): Purified with $50 \%$ EtOAc/hexanes, to give $113 \mathrm{mg}(95 \%)$ of 24 as a colorless oil. $\mathrm{R} f=0.33$ (90\% ether/hexanes); IR (film) 3079, 3063, 3028, 2921, 1715, 1675, $1412 \mathrm{~cm}^{-1}$; $\left.{ }^{1} \mathrm{H} \mathrm{NMR} \mathrm{(500} \mathrm{MHz}, \mathrm{CDCl}_{3}\right) \delta$ $7.33-7.25(\mathrm{~m}, 5 \mathrm{H}), 7.11(\mathrm{~s}, 1 \mathrm{H}), 7.00(\mathrm{~s}, 1 \mathrm{H}), 4.30(\mathrm{dd}, J=10.5,3.5$ $\mathrm{Hz}, 1 \mathrm{H}), 4.19$ (dd, $J=18.0,10.5 \mathrm{~Hz}, 1 \mathrm{H}), 3.94$ (s, 3H), 3.29 (dd, $J=18.0,3.5 \mathrm{~Hz}, 1 \mathrm{H}), 2.46$ (dd, $J=16.5,6.0 \mathrm{~Hz}, 1 \mathrm{H}), 2.28(\mathrm{dd}, J=16.5,7.5 \mathrm{~Hz}, 1 \mathrm{H}), 2.13(\mathrm{sep}, J=7.0 \mathrm{~Hz}, 1 \mathrm{H}), 0.88(\mathrm{~d}, J=6.5$ $\mathrm{Hz}, 3 \mathrm{H}), 0.72(\mathrm{~d}, J=6.5 \mathrm{~Hz}, 3 \mathrm{H}) ;{ }^{13} \mathrm{C} \mathrm{NMR}\left(125 \mathrm{MHz}, \mathrm{CDCl}_{3}\right) \delta 208.5,190.5,142.5,137.7$, 129.0, 128.8, 128.4, 127.3, 126.7, 53.6, 50.3, 42.1, 35.9, 24.0, 22.5, 22.1; LRMS (electrospray): Mass calculated for $\mathrm{C}_{18} \mathrm{H}_{20} \mathrm{~N}_{2} \mathrm{O}_{2}[\mathrm{M}]^{+}, 296.15$. Found 297.

\section{Larger Scale (5 mmol) Preparation of 7}

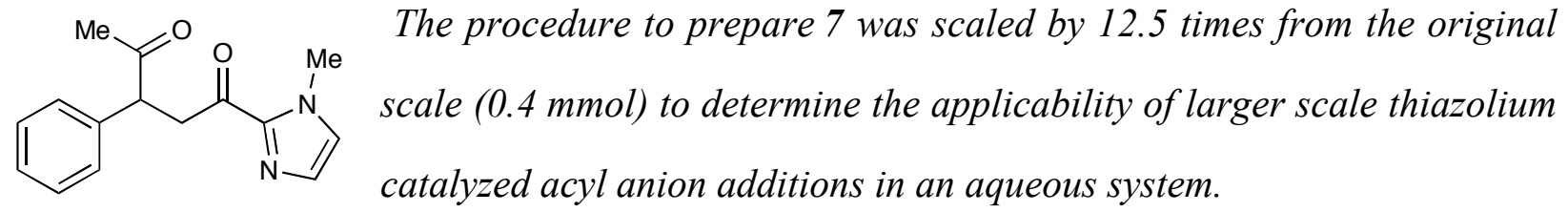

A $50 \mathrm{~mL}$ RBF was charged with 3-benzyl-5-(2-hydroxyethyl)-4-methyl-thiazolium chloride (5) (thiazole carbene precursor) (269 mg, $1.0 \mathrm{mmol}, 20 \mathrm{~mol} \%$ ), sodium pyruvate (1b) (990 mg, 9.0 mmol, 1.8 equiv), and 2-cinnamoyl-1-methyl-1H-imidazole (6) (1.06 g, 5.0 mmol, 1.0 equiv) on the benchtop. Next, $\mathrm{MeOH}(9.0 \mathrm{~mL})$ and $\mathrm{pH} 7.2$ phosphate buffer $(6.0 \mathrm{~mL}, 100 \mathrm{mM}$, were added via syringe to the reaction flask. The resulting mixture was heated to $70{ }^{\circ} \mathrm{C}$ and allowed 
to stir for $16 \mathrm{~h}$. The reaction was cooled to room temperature, diluted with EtOAc $(50 \mathrm{~mL})$ and transferred to a separatory funnel. Saturated $\mathrm{NaCl}(25 \mathrm{~mL})$, saturated $\mathrm{NaHCO}_{3}(25 \mathrm{~mL})$, and $\mathrm{H}_{2} \mathrm{O}(15 \mathrm{ml})$ were added and the aqueous layer was extracted with EtOAc $(3 \times 100 \mathrm{~mL})$. The combined organic extracts were dried over sodium sulfate, filtered, and concentrated on a rotary evaporator. The residue was purified by flash column chromatography $40 \%$ EtOAc/hexanes, to give $1.14 \mathrm{~g}(89 \%)$ of 7 as a white solid.

\section{General procedure $\mathrm{E}$ for the preparation of 8 and 10 in ethylene glycol at $23{ }^{\circ} \mathrm{C}$}

A $25 \mathrm{~mL}$ RBF was charged with 3-benzyl-5-(2-hydroxyethyl)-4-methyl-thiazolium chloride (5) (thiazole carbene precursor) (161 mg, $0.6 \mathrm{mmol}, 30 \mathrm{~mol} \%$ ), sodium pyruvate (1b) (400 mg, 3.6 mmol, 1.8 equiv), and $\alpha, \beta$-unsaturated-keto- $N$-methylimidazole substrate ( $2.0 \mathrm{mmol}, 1.0$ equiv) on the benchtop. Next, ethylene glycol $(5.0 \mathrm{~mL})$ and DBU $(90 \mu \mathrm{L}, 0.6 \mathrm{mmol}, 30 \mathrm{~mol} \%)$ were added via syringe to the reaction flask. The resulting mixture was stirred at $23{ }^{\circ} \mathrm{C}$ for 6 to $8 \mathrm{~h}$. The reaction was diluted with $\mathrm{H}_{2} \mathrm{O}(15 \mathrm{~mL})$, filtered, and washed with additional $\mathrm{H}_{2} \mathrm{O}(2 \times 20$ $\mathrm{mL}$ ). The resulting products $\mathbf{8}$ and $\mathbf{1 0}$ were dried by filtering for $10 \mathrm{~min}$ and placed under high vacuum overnight. The 1,4-diketone products $\mathbf{8}$ and $\mathbf{1 0}$ prepared using this procedure were as pure as the same products prepared in the aqueous system with subsequent column chromatography.

\section{Experimental details of the product inhibition study}

Product inhibition studies utilized $\alpha, \beta$-unsaturated-keto- $N$-methylimidazole 8a as the conjugate acceptor due to its higher solubility in $\mathrm{MeOH}$ at $23{ }^{\circ} \mathrm{C}$ over compound 6 .

\section{Reaction Procedure Without Product 8 as an Additive}

A screw-capped tube was charged with 3-benzyl-5-(2-hydroxyethyl)-4-methyl-thiazolium chloride (5) (thiazole carbene precursor) (14 $\mathrm{mg}, 0.05 \mathrm{mmol}, 26 \mathrm{~mol} \%$ ), sodium pyruvate (1b) (40 mg, 0.36 mmol, 1.8 equiv), and $\alpha, \beta$-unsaturated-keto- $N$-methylimidazole substrate $8 \mathbf{a}(0.2$ mmol, 1.0 equiv) on the benchtop. Next, $\mathrm{MeOH}(750 \mu \mathrm{L})$ and $\mathrm{DBU}(12 \mu \mathrm{L}, 0.08 \mathrm{mmol}, 40$ mol\%) were added via syringe to the screw-capped tube. The resulting mixture was stirred at 23 ${ }^{\circ} \mathrm{C}$ for an allotted time. After stirring for the appropriate time period $(2.25 \mathrm{~h}$ to $21.25 \mathrm{~h})$ the reactions were diluted with EtOAc $(4 \mathrm{~mL})$ and a portion was run through a silica gel plug 
(pipette size) before GC analysis. Experiments were monitored by GC and starting material 8a : product 8 ratios were determined by peak integrations. Starting material and products peak integrations were linear over numerous mole fraction ratios $(1: 2,2: 2,2: 1)$.

\section{Reaction Procedure With Product 8 as an Additive}

A screw-capped tube was charged with 3-benzyl-5-(2-hydroxyethyl)-4-methyl-thiazolium chloride (5) (thiazole carbene precursor) (14 $\mathrm{mg}, 0.05 \mathrm{mmol}, 26 \mathrm{~mol} \%$ ), sodium pyruvate (1b) (40 mg, 0.36 mmol, 1.8 equiv), $\alpha, \beta$-unsaturated-keto- $N$-methylimidazole substrate 8a (45 mg, $0.2 \mathrm{mmol}, 1.0$ equiv), and product 8 ( $54 \mathrm{mg}, 0.2 \mathrm{mmol}, 1.0$ equiv) on the benchtop. Next, $\mathrm{MeOH}(750 \mu \mathrm{L})$ and $\mathrm{DBU}(12 \mu \mathrm{L}, 0.08 \mathrm{mmol}, 40 \mathrm{~mol} \%)$ were added via syringe to the screwcapped tube. The resulting mixture was stirred at $23{ }^{\circ} \mathrm{C}$ for an allotted time. After stirring for the appropriate time period $(2.25 \mathrm{~h}$ to $21.25 \mathrm{~h})$ the reactions were diluted with EtOAc ( $4 \mathrm{~mL})$ and a portion was run through a silica gel plug (pipette size) before GC analysis. Experiments were monitored by $\mathrm{GC}$ and starting material $\mathbf{8 a}$ : product $\mathbf{8}$ ratios were determined by peak integrations. Starting material and products peak integrations were linear over numerous mole fraction ratios $(1: 2,2: 2,2: 1)$.

Results from the product inhibition study show depressed conversion when 8 (1.0 equiv.) is used as an additive. This strongly indicates product inhibition at $23{ }^{\circ} \mathrm{C}$, however, when these reactions are conducted at $70{ }^{\circ} \mathrm{C}$ the reactions go to $100 \%$ conversion. Below is a summary of the results in tabular and graphical format.

\begin{tabular}{ccc}
\cline { 2 - 3 } & Conversion (\%) & Time $(\mathrm{h})$ \\
\cline { 2 - 3 } & 20 & 2.25 \\
Without & 24 & 5.10 \\
Additive 8 & 29 & 10.20 \\
& 32 & 15.20 \\
& 35 & 21.25 \\
With & 9 & 2.25 \\
Additive 8 & 13 & 5.10 \\
& 13 & 10.20 \\
& 13 & 15.20 \\
& 13 & 21.25 \\
\hline
\end{tabular}

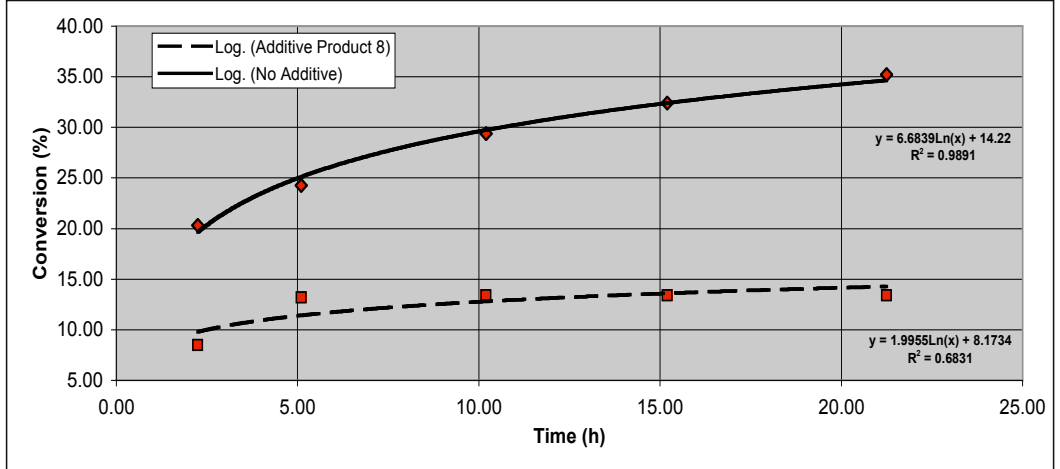

GC Analysis Conditions: $70{ }^{\circ} \mathrm{C}$ hold $1 \mathrm{~min} .20^{\circ} \mathrm{C} / \mathrm{min}$ ramp up to $285^{\circ} \mathrm{C}$ and holding for 3.25 min. Total run time $15 \mathrm{~min} . t_{\mathrm{R}}(\mathbf{8 a})=12.62 \mathrm{~min}, t_{\mathrm{R}}(\mathbf{8})=12.73 \mathrm{~min}$ with baseline separation. 


\section{Preparation of methyl ester ${ }^{1,8} \mathbf{2 6}$ and morpholine amide 27 from 7}

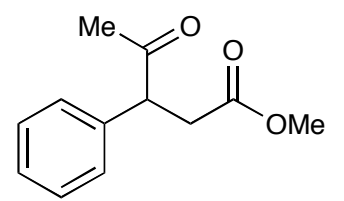

Methyl-4-oxo-3-phenylpentanoate (26): 1-(1-methyl-1H-imidazol-2-yl)3-phenylpentane-1,4-dione (7) (128 mg, $0.5 \mathrm{mmol}, 1.0$ equiv) was added to a screw-cap tube followed by $\mathrm{CH}_{2} \mathrm{Cl}_{2}(1.5 \mathrm{~mL})$. The solution was stirred and MeOTf ( $280 \mu \mathrm{L}, 2.5 \mathrm{mmol}, 5.0$ equiv) was added dropwise. The solution was stirred at 23 ${ }^{\circ} \mathrm{C}$ for $5 \mathrm{~h}$. A solution of $\mathrm{MeOH}(1.0 \mathrm{~mL}, 25.0 \mathrm{mmol}, 50$ equiv) and DABCO (1.1 mL, 10.0 mmol, 20 equiv) was prepared and added slowly to the reaction tube. An addition portion of $\mathrm{CH}_{2} \mathrm{Cl}_{2}(1.5 \mathrm{~mL})$ was added to the reaction tube. The mixture stirred at $23{ }^{\circ} \mathrm{C}$ for an additional 4 h. The mixture was diluted with EtOAc $(10 \mathrm{~mL})$ and transferred to a separatory funnel. Saturated $\mathrm{NaCl}(20 \mathrm{~mL})$, and $\mathrm{H}_{2} \mathrm{O}(20 \mathrm{ml})$ were added and the aqueous layer was extracted with EtOAc (4 x $40 \mathrm{~mL})$. The combined organic extracts were dried over sodium sulfate, filtered, and concentrated on a rotary evaporator. The residue was purified by flash column chromatography $30 \%$ EtOAc/hexanes, to give $79 \mathrm{mg}(78 \%)$ of 26 as a colorless oil. $\mathrm{R} f=0.55(30 \%$ EtOAc/hexanes); IR (film) 3028, 2953, 1737, $1717 \mathrm{~cm}^{-1} ;{ }^{1} \mathrm{H}$ NMR (500 MHz, $\left.\mathrm{CDCl}_{3}\right) \delta 7.33$ (t, $J=7.5 \mathrm{~Hz}, 2 \mathrm{H}), 7.28(\mathrm{t}, J=7.0 \mathrm{~Hz}, 1 \mathrm{H}), 7.21(\mathrm{t}, J=7.0 \mathrm{~Hz}, 2 \mathrm{H}), 4.19(\mathrm{dd}, J=10.0,5.0 \mathrm{~Hz}$, $1 \mathrm{H}), 3.64(\mathrm{~s}, 3 \mathrm{H}), 3.21(\mathrm{dd}, J=16.5,10.0 \mathrm{~Hz}, 1 \mathrm{H}), 2.52(\mathrm{dd}, J=17.0,5.0 \mathrm{~Hz}, 1 \mathrm{H}), 2.10(\mathrm{~s}, 3 \mathrm{H})$; ${ }^{13} \mathrm{C}$ NMR $\left(125 \mathrm{MHz}, \mathrm{CDCl}_{3}\right) \delta$ 206.6, 172.4, 137.3, 129.1, 128.1, 127.6, 54.7, 51.7, 36.6, 28.7; LRMS (electrospray): Mass calculated for $\mathrm{C}_{12} \mathrm{H}_{14} \mathrm{NaO}_{3}[\mathrm{M}+\mathrm{Na}]^{+}$, 229.23. Found 229. Spectroscopic data were consistent with the literature data for this compound. ${ }^{9}$<smiles>CC(=O)C(CC(=O)N1CCOCC1)c1ccccc1</smiles>

1-morpholine-3-phenylpentane-1,4-dione (27): 1-(1-methyl-1Himidazol-2-yl)-3-phenylpentane-1,4-dione (7) (128 mg, $0.5 \mathrm{mmol}, 1.0$ equiv) was added to a screw-cap tube followed by $\mathrm{CH}_{2} \mathrm{Cl}_{2}(1.5 \mathrm{~mL})$. The solution was stirred and $\operatorname{MeOTf}(280 \mu \mathrm{L}, 2.5 \mathrm{mmol}, 5.0$ equiv) was added dropwise. The solution was stirred at $23{ }^{\circ} \mathrm{C}$ for $5 \mathrm{~h}$. Next, morpholine $(1.1 \mathrm{~mL}, 12.5 \mathrm{mmol}, 25$ equiv) was added slowly to the reaction tube. An addition portion of $\mathrm{CH}_{2} \mathrm{Cl}_{2}(1.5 \mathrm{~mL})$ and DMAP $(6.0 \mathrm{mg}$, $0.05 \mathrm{mmol}, 10 \mathrm{~mol} \%$ ) were added to the reaction tube. The mixture stirred at $23{ }^{\circ} \mathrm{C}$ for an additional $4 \mathrm{~h}$. The mixture was diluted with EtOAc $(10 \mathrm{~mL})$ and transferred to a separatory funnel. Saturated $\mathrm{NaCl}(20 \mathrm{~mL})$, and $\mathrm{H}_{2} \mathrm{O}(20 \mathrm{ml})$ were added and the aqueous layer was

\footnotetext{
${ }^{8}$ Bakhtiar, C.; Smith, E. H. J. Chem. Soc. Perkin Trans. 1 1994, 239-243.

9 Nozaki, K.; Komaki, H.; Kawashima, Y.; Hiyama, T.; Matsubara, T. J. Am. Chem. Soc. 2001, 123, 534-544.
} 
extracted with EtOAc $(4 \times 40 \mathrm{~mL})$. The combined organic extracts were dried over sodium sulfate, filtered, and concentrated on a rotary evaporator. The residue was purified by flash column chromatography 95\% EtOAc/hexanes, to give $122 \mathrm{mg}$ (94\%) of 27 as a colorless oil. $\mathrm{R} f$ $=0.40$ (95\% EtOAc/hexanes); IR (film) 2965, 2920, 2858, 1728, $1660 \mathrm{~cm}^{-1} ;{ }^{1} \mathrm{H}$ NMR (500 MHz, DMSO) $\delta$ 7.36-7.26 (m, 5H), 4.26 (dd, $J=10.5,3.5 \mathrm{~Hz}, 1 \mathrm{H}), 3.58-3.36$ (m, 8H), 3.22 (dd, $J=16.5,11.0 \mathrm{~Hz}, 1 \mathrm{H}), 2.55(\mathrm{dd}, J=16.5,3.5 \mathrm{~Hz}, 1 \mathrm{H}), 2.09$ (s, 3H); ${ }^{13} \mathrm{C}$ NMR $(125 \mathrm{MHz}$, DMSO) $\delta$ 207.1, 169.2, 138.0, 128.8, 128.3, 127.3, 66.1, 53.7, 45.2, 41.5, 36.0, 29.0; LRMS (electrospray): Mass calculated for $\mathrm{C}_{15} \mathrm{H}_{19} \mathrm{NNaO}_{3}[\mathrm{M}+\mathrm{Na}]^{+}$, 284.31. Found 284 . 


\section{Selected NMR spectra}
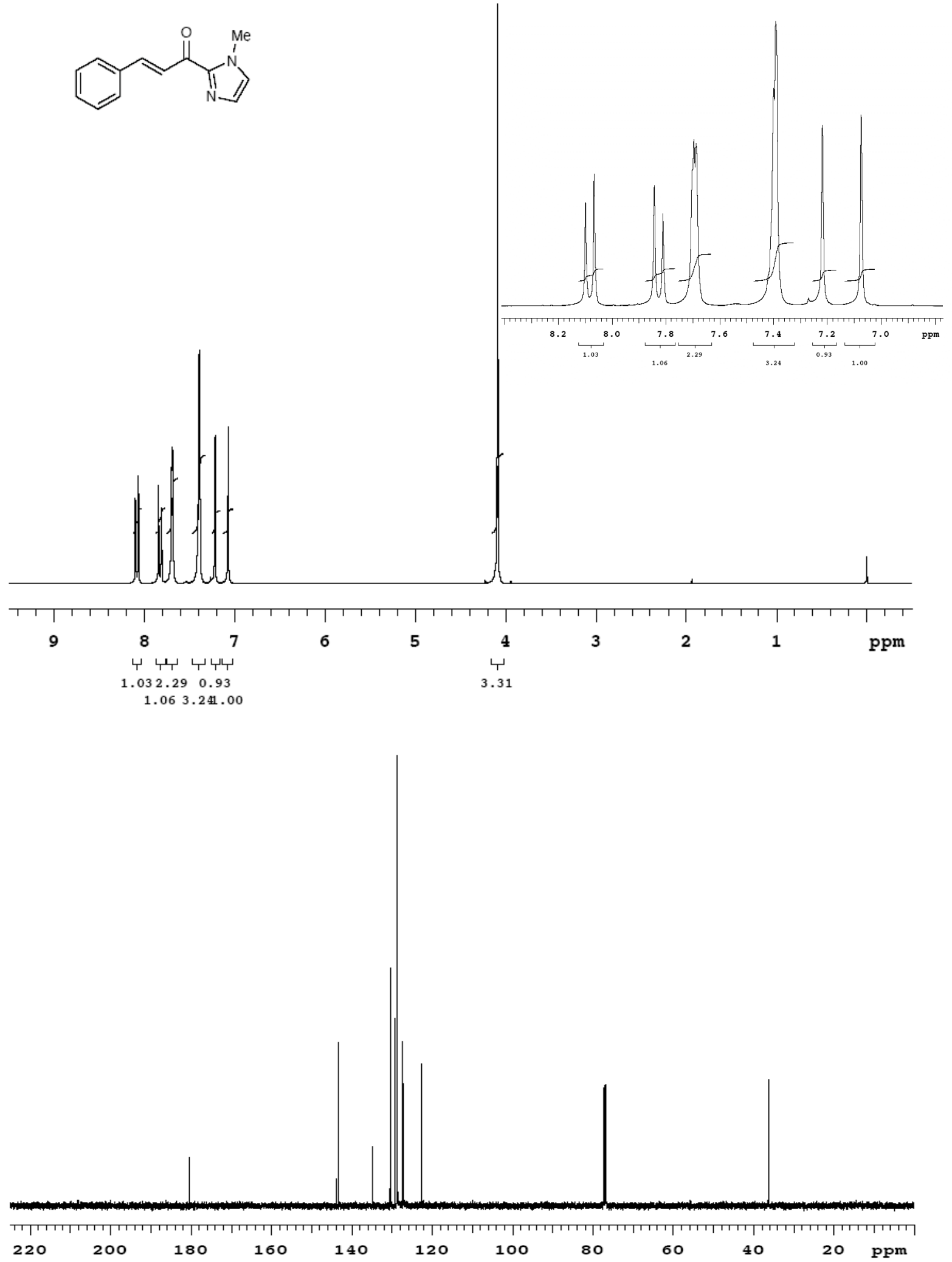

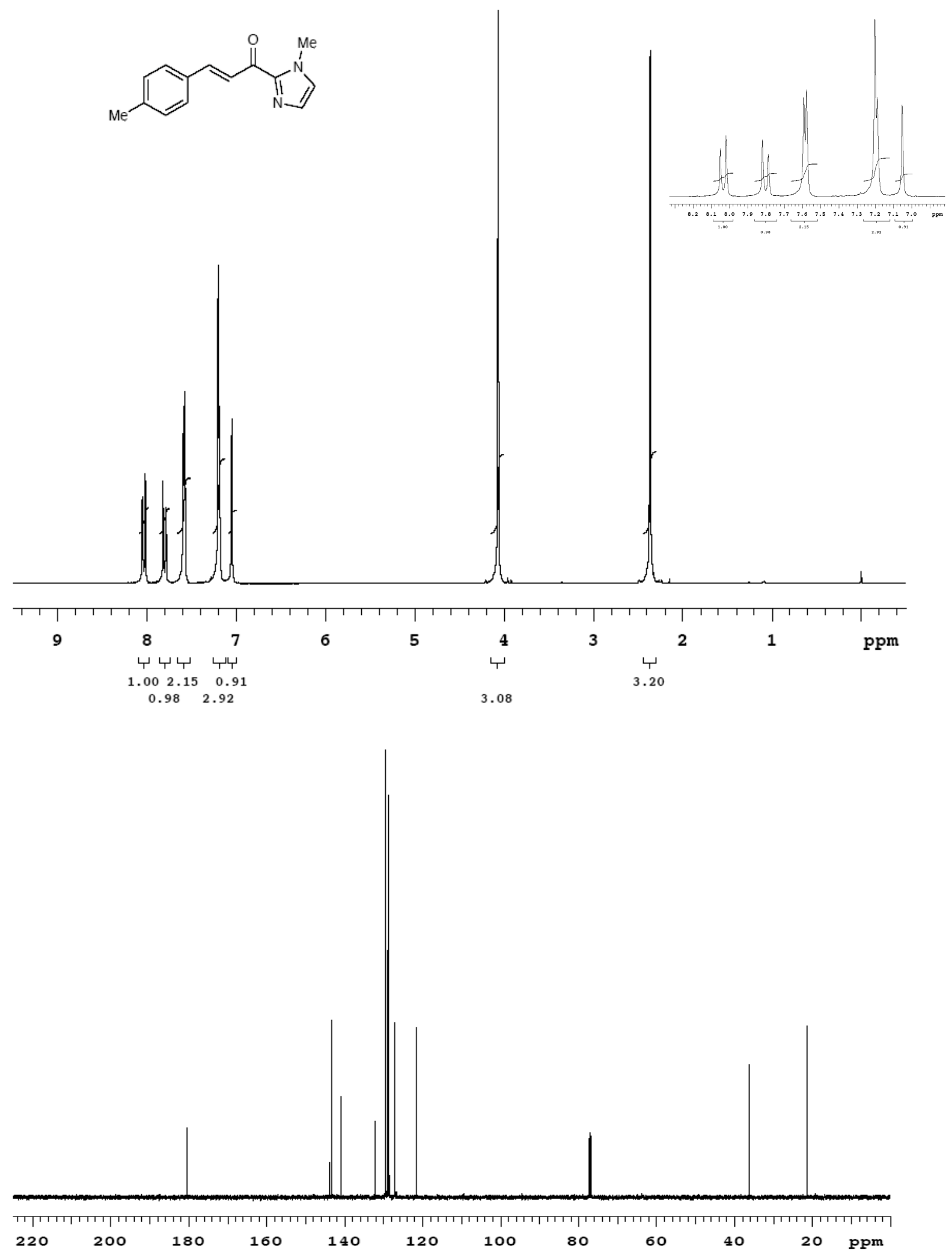


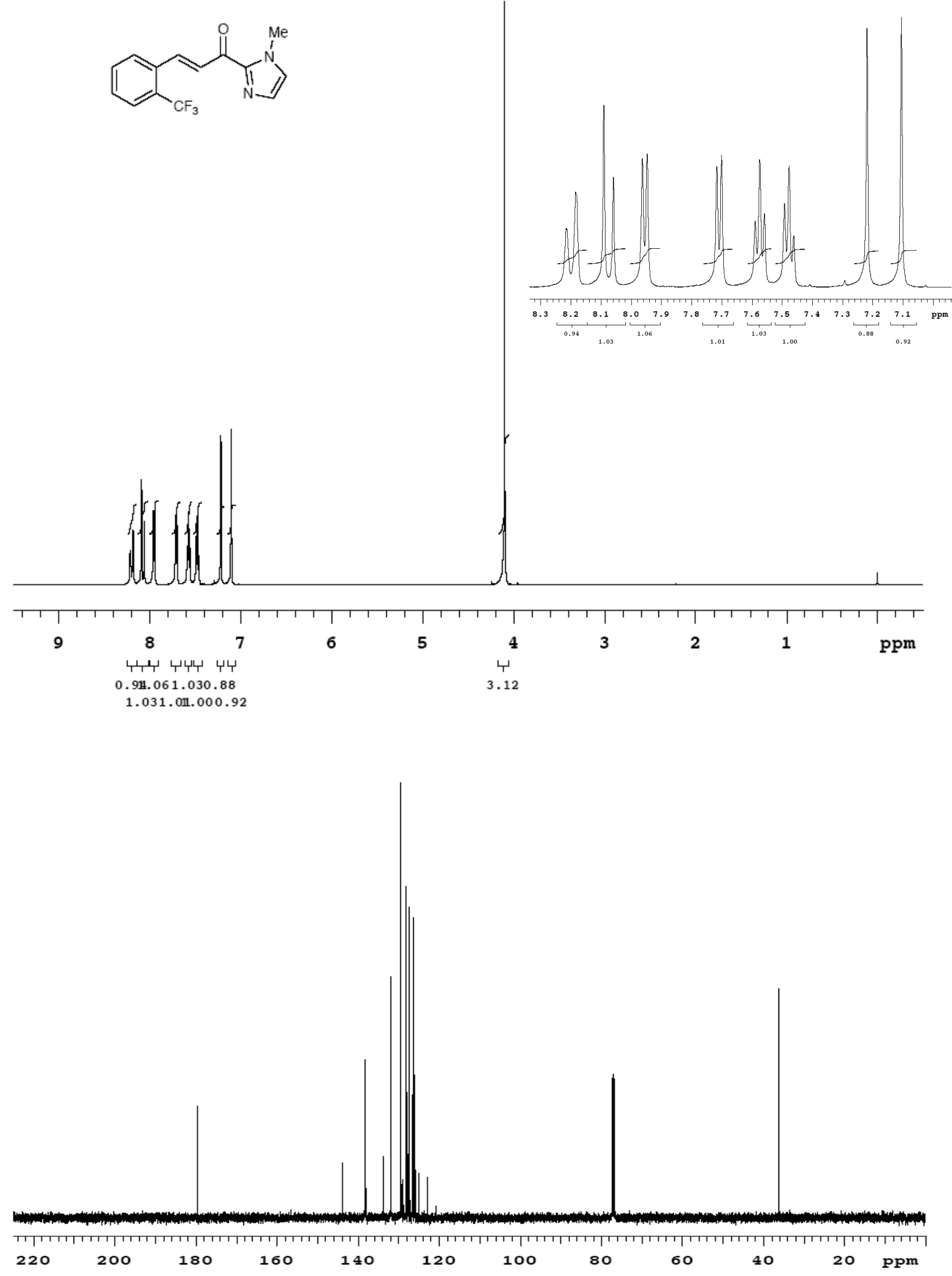



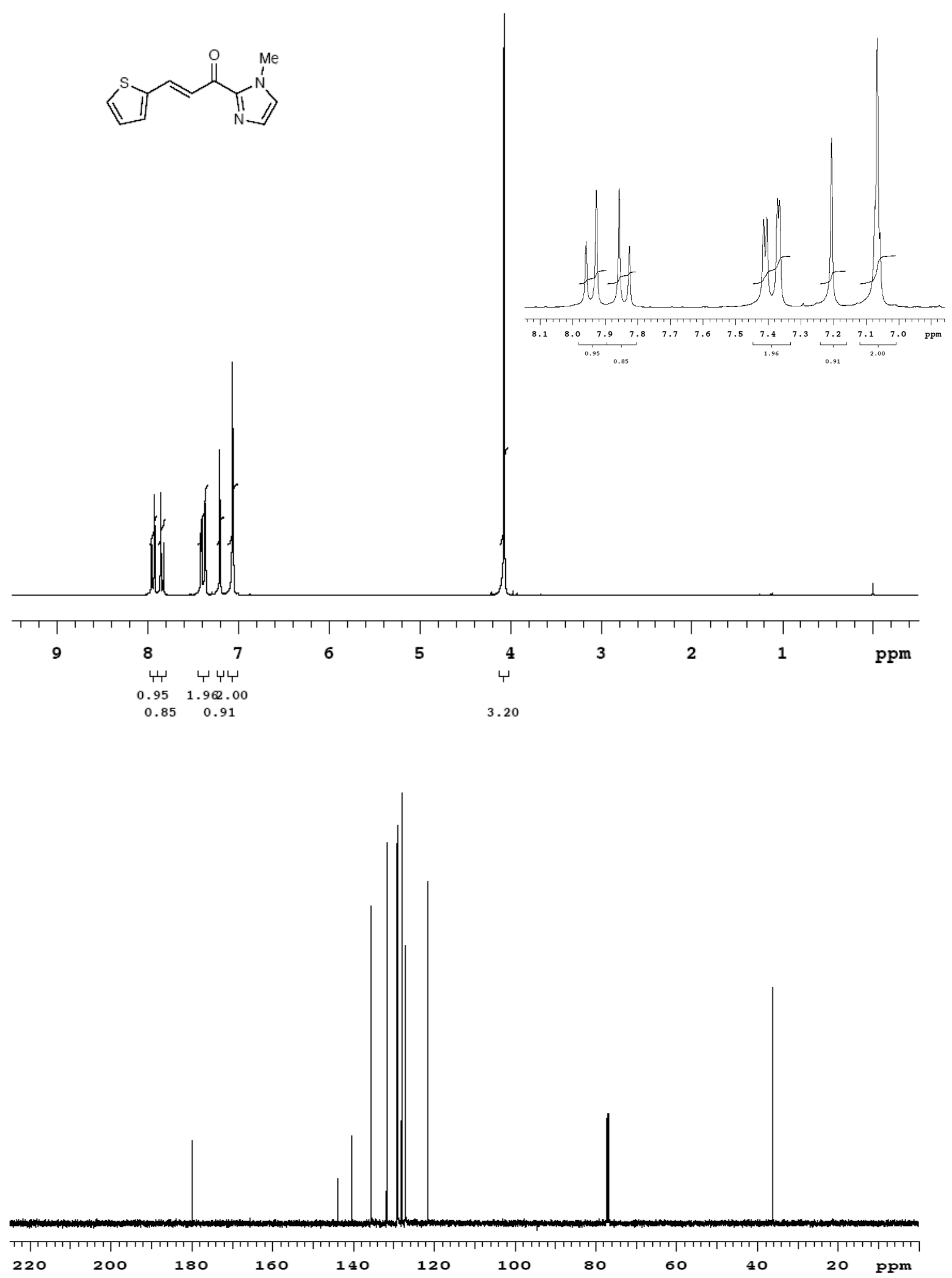

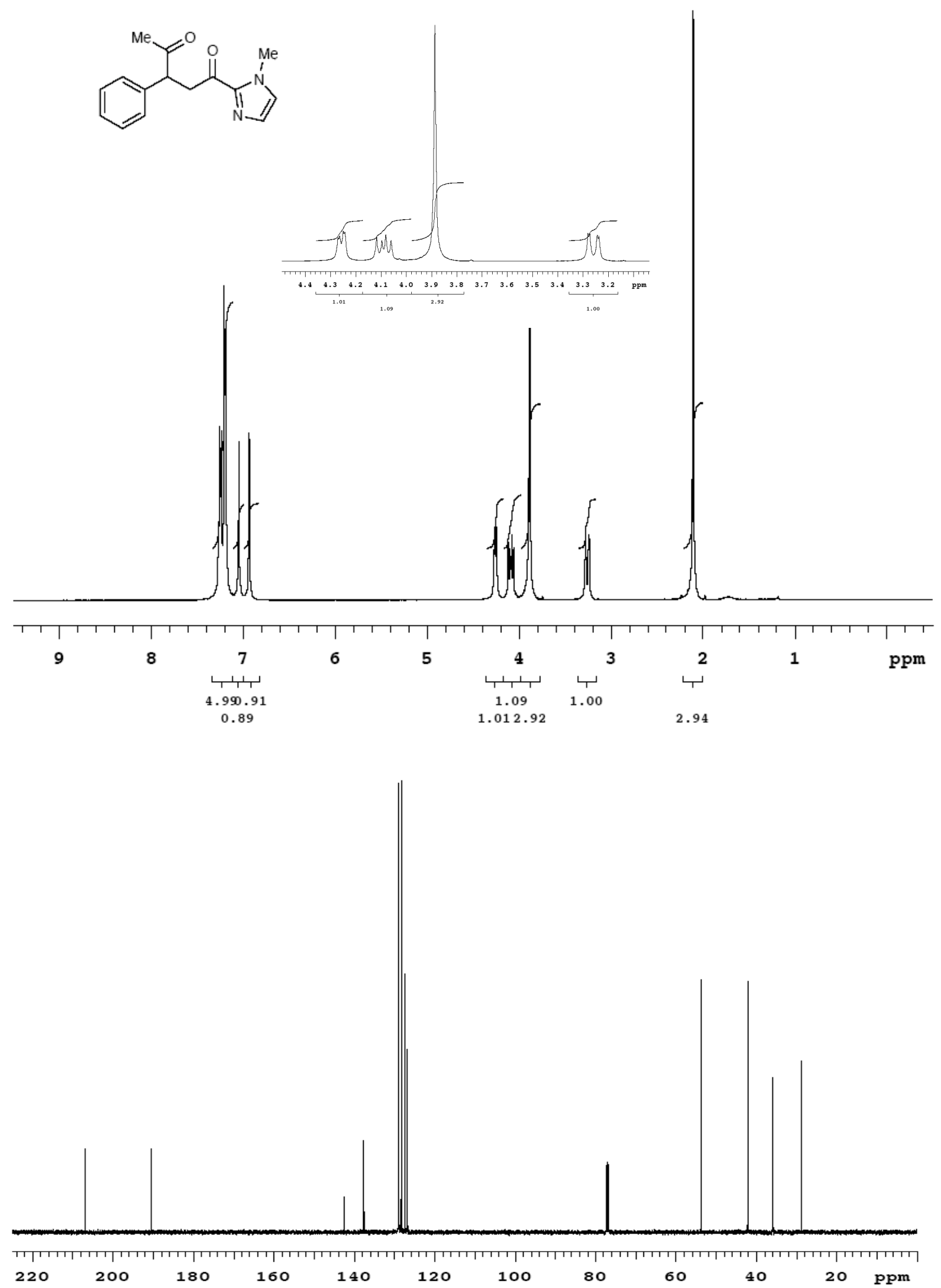

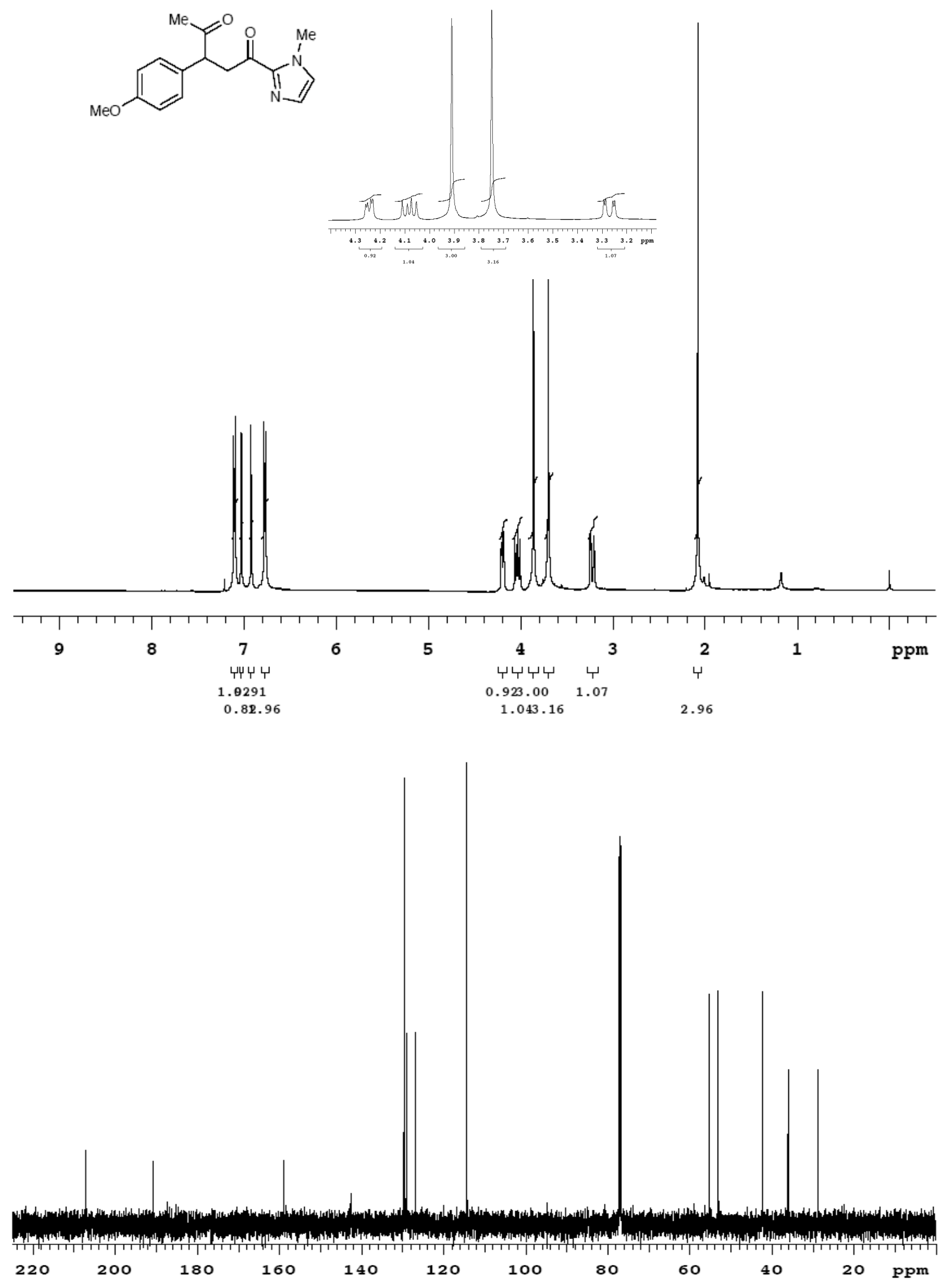

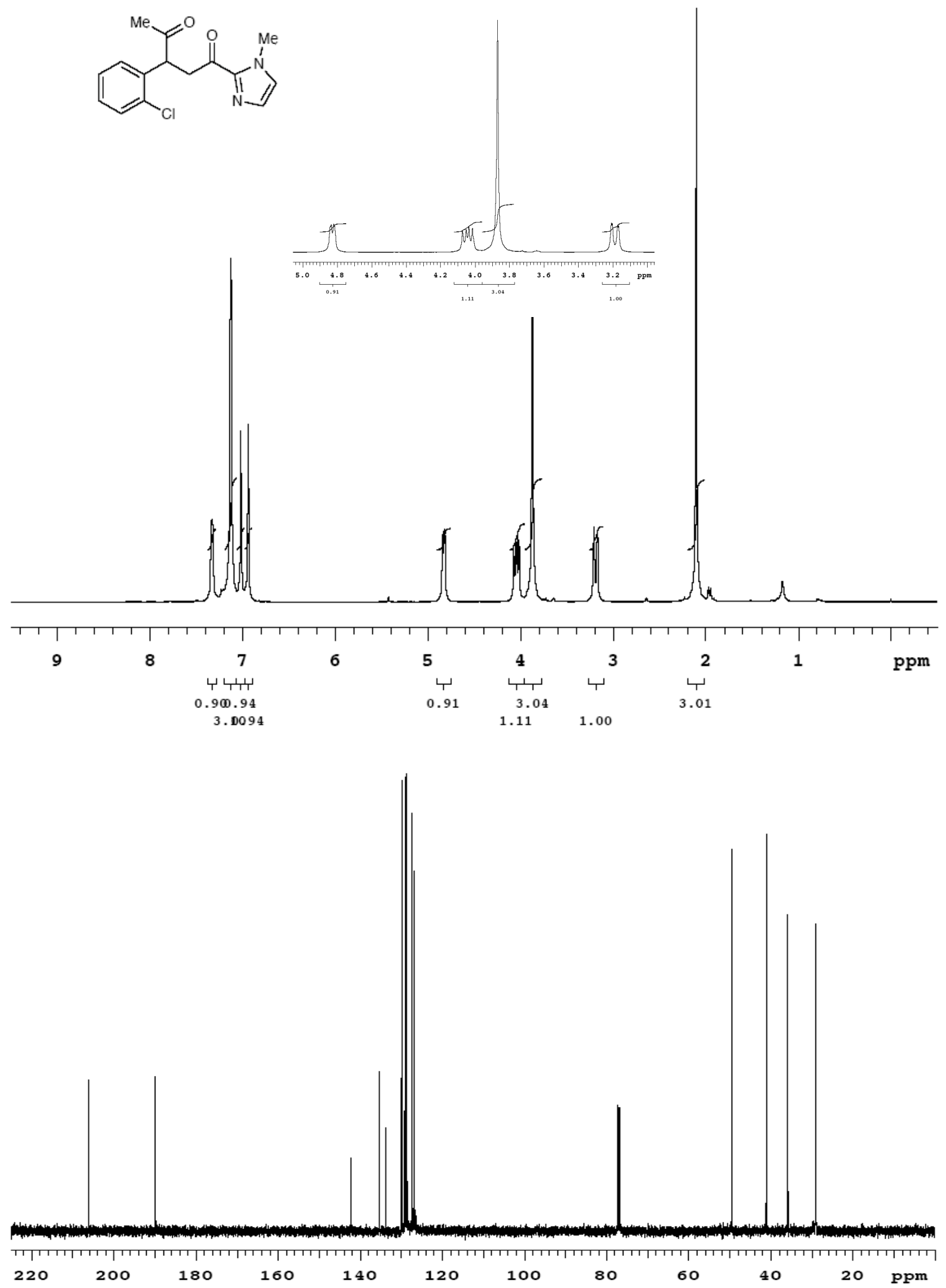

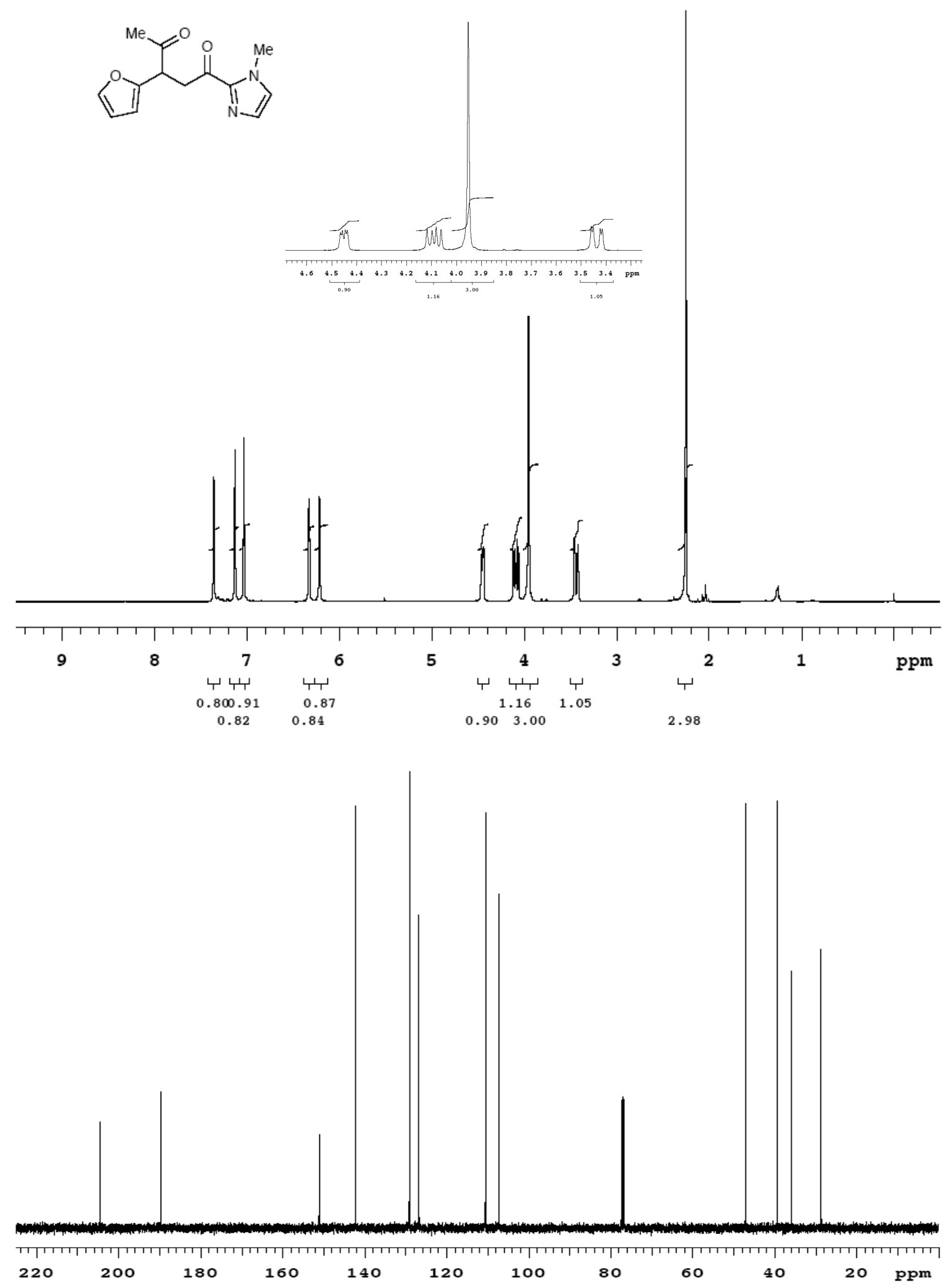


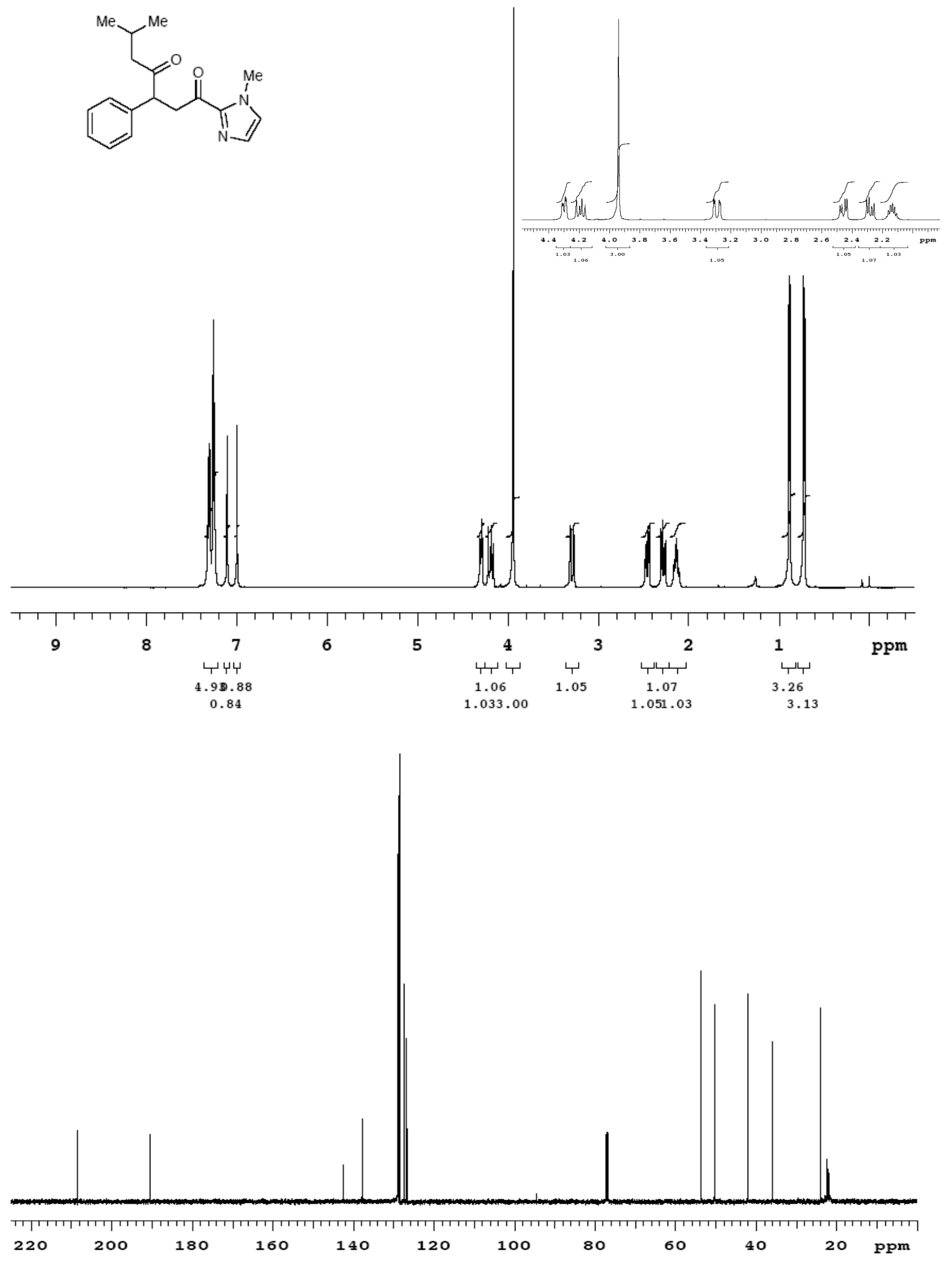




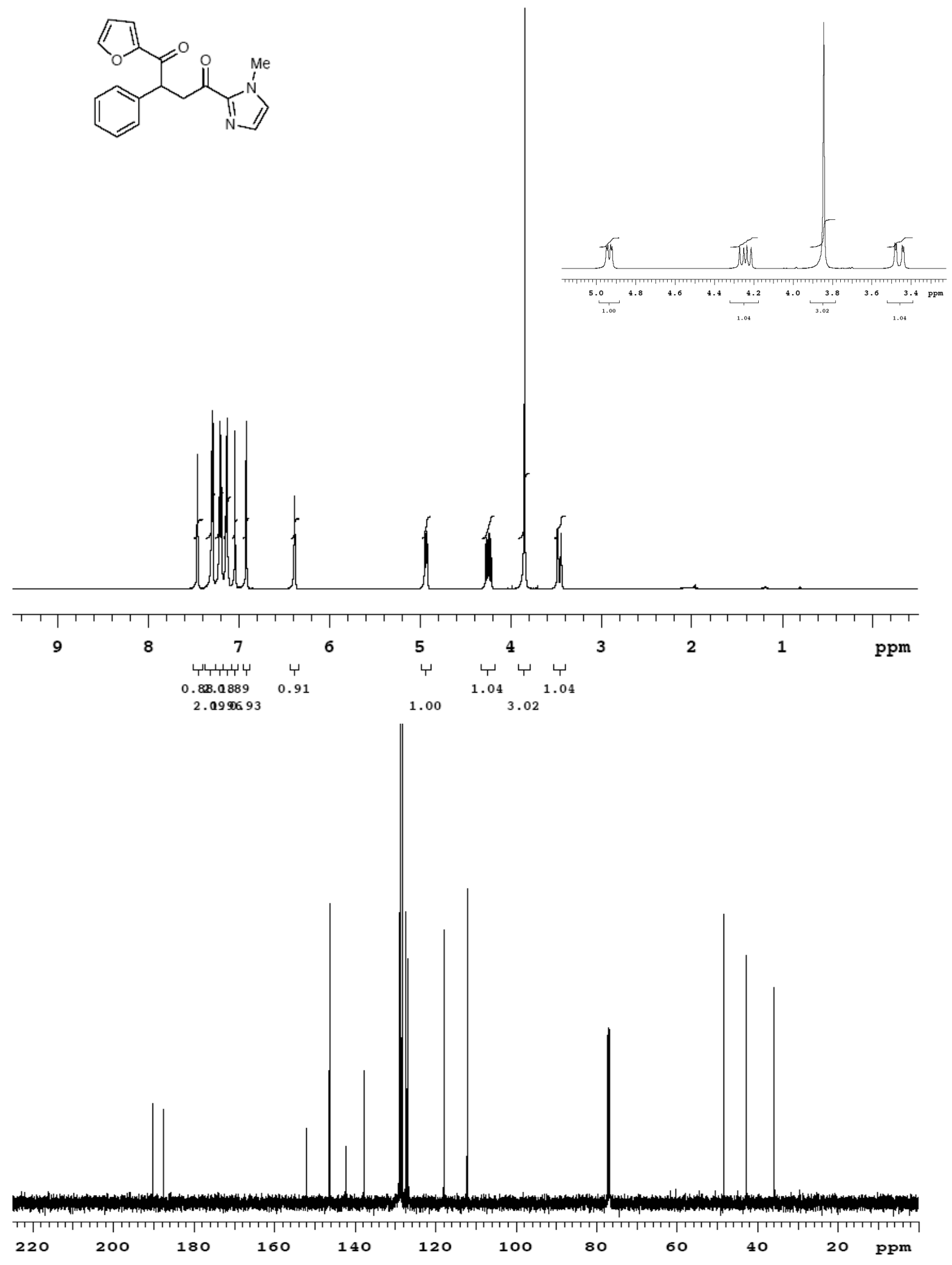



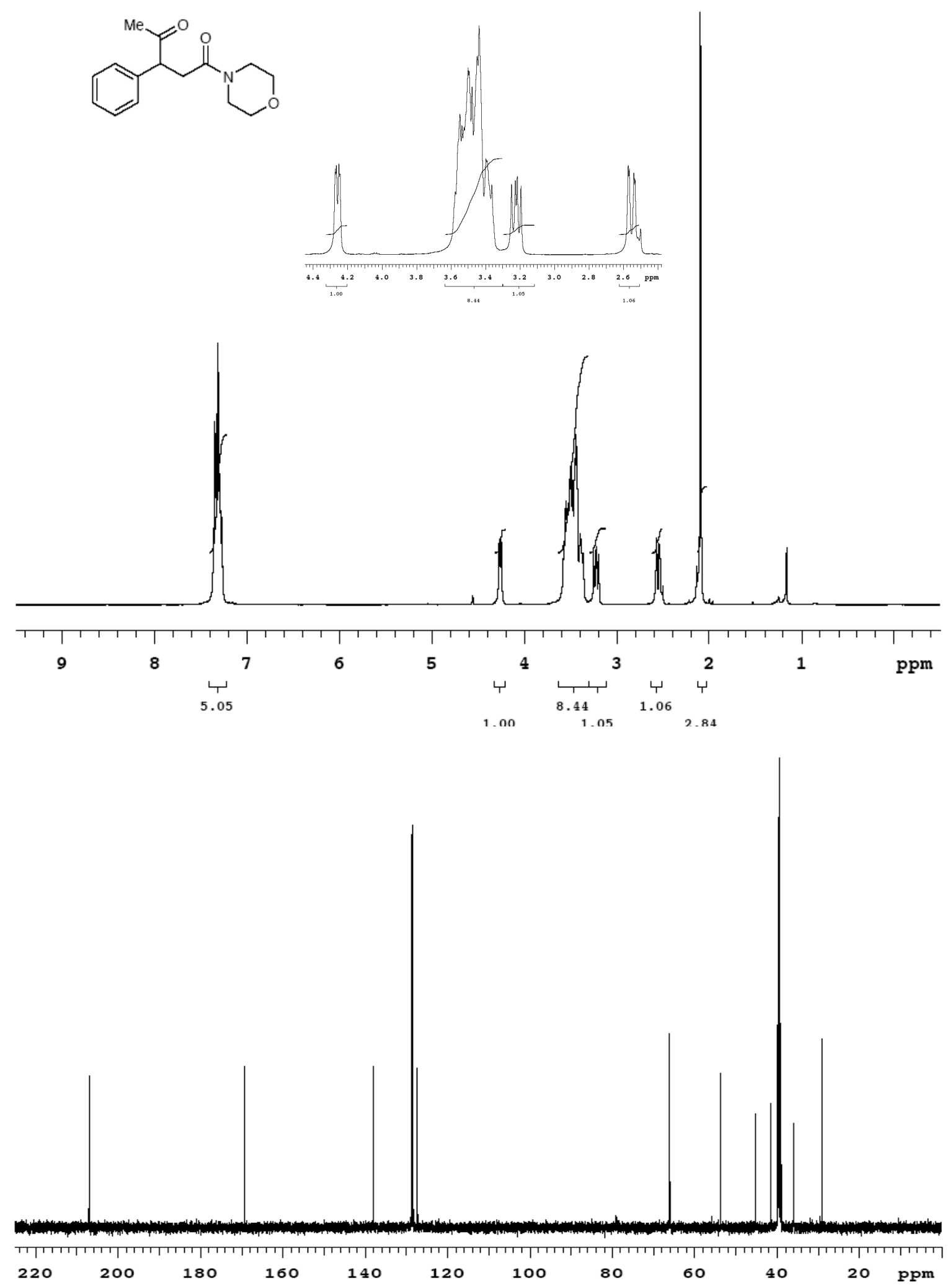